\title{
Metamorfosis editoriales y construcción de un texto clásico: el caso de Formes urbaines: de l'îlot à la barre (1977-1997)*
}

\author{
Editorial metamorphoses and construction of a classic book: the case of Formes \\ urbaines: de l'îlot à la barre (1977-1997)
}

\section{Pierre Chabard}

Ecole Nationale Supérieure d'Architecture Paris-La Villette. París (Francia)

\section{Traductores: \\ Andrés Ávila-Gómez}

Université Paris I Panthéon-Sorbonne. París (Francia)

\section{Diana Carolina Ruiz}

Université Paris IV Paris-Sorbonne

Chabard, P., Ávila-Gómez, A., \& Ruiz, D. C. (202I). Metamorfosis editoriales y construcción de un texto clásico: el caso de Formes urbaines: de l'îlot à la barre (1977-1997). Revista de Arquitectura (Bogotá), 23(2). https://doi. org/10.14718/RevArq.2021.3814

\section{Pierre Chabard}

Doctor en Architecture : Université Paris VIII.

DEA - Master Projet architectural et urbain : ENSA Paris-Belleville. Architecte DPLG : ENSA Paris-Belleville.

Profesor titular en la Ecole Nationale Supérieure d'Architecture de Paris-La Villette.

Investigador asociado : laboratorio Architecture - Histoire - Technique - Territoire - Patrimoine (AHTTEP)

Fundador de la revista Criticat

https://umrausser.cnrs.fr/pierre-chabard

https://umrausser.cnrs.fr/pierre-chabard

https://criticat.fr/

(1) chabard@criticat.fr

Andrés Ávila-Gómez

Magíster en Urbanismo, Universidad Nacional de Colombia.

Magíster en Ville, architecture, patrimoine, Université Paris 7 Diderot \& ÉNSA Paris-Val de Seine.

Doctorando en Histoire de l'Art, Université Paris I Panthéon-Sorbonne (École doctorale 44I).

Investigador asociado del Centre de Recherche HiCSA - Histoire culturelle et sociale des arts, Université Paris I Panthéon-Sorbonne. https://univ-paris I.academia.edu/AndresÁvila

(iD) http://orcid.org/0000-0003-3883-2737

andresavigom@gmail.co

\section{Diana Carolina Ruiz}

Profesional en Langues Etrangères Appliquées, U. Paris IV Paris-Sor-

bonne
Master en Etudes hispaniques et hispano-américaines, U. Paris IV Paris-Sorbonne

Traductora para revistas de arquitectura, patrimonio e historia del arte (Atrio; Dearq; Apuntes; Academia XXII)

\section{(c) (i) (5)}

https://doi.org/10.14718/RevArq.2021.3814

(D) http://orcid.org/0000-000I-5524-0456

(0) karorr2002@gmail.com

\section{Resumen}

El presente artículo aborda aspectos ligados a la concepción, producción, difusión, y recepción de un texto cuya importancia en la historiografía de la arquitectura y el urbanismo lo han erigido en una obra de referencia imprescindible entre estudiantes y profesionales de estas disciplinas: se trata de Formes urbaines: de l'îlot à la barre. Traducido al español por el arquitecto Santiago Castán, y publicado por primera vez en 1986 bajo el título De la manzana al bloque por la editorial Gustavo Gili, constituye un verdadero manifiesto cuyas preocupaciones de carácter pedagógico reflejan en buena medida aquellas propias del ejercicio de la arquitectura durante el último cuarto del siglo XX. Evitando toda lectura antihistórica, el análisis aquí propuesto se apoya en una serie de aproximaciones y reflexiones para las cuales hemos reconstruido (gracias principalmente a entrevistas realizadas directamente a los protagonistas del relato, y a la consulta de sus archivos) el contexto sociocultural inmediato que hizo posible la realización del estudio inicial que dio origen al libro, en el marco de una reorganización profunda de la enseñanza de la arquitectura y del urbanismo en Francia (tras la disolución en Mayo de 1968 de la sección de Arquitectura de la École des Beaux-Arts).

Palabras clave: investigación interdisciplinaria; metodología; enseñanza de la arquitectura; ciencias sociales; urbanismo; arquitectura.

\section{Abstract}

This article addresses aspects related to the conception, production, dissemination, and reception of a text whose importance in the historiography of architecture and urbanism has made it an essential reference work among students and professionals in these disciplines: it is about Formes urbaines: from l'îlot à la barre. Translated into Spanish by the architect Santiago Castán, and published for the first time in 1986 under the title From the apple to the block by the Gustavo Gili publishing house, it constitutes a true manifesto whose pedagogical concerns largely reflect those of the practice of architecture. during the last quarter of the 20th century. Avoiding any anti-historical reading, the analysis proposed here is supported by a series of approaches and reflections for which we have reconstructed (thanks mainly to interviews carried out directly with the protagonists of the story, and by consulting their archives) the immediate sociocultural context that made possible the realization of the initial study that gave rise to the book, within the framework of a profound reorganization of the teaching of architecture and urban planning in France (after the dissolution in May 1968 of the Architecture section of the École des Beaux-Arts)

Keyword: interdisciplinary research, methodology, architecture education, social sciences, urban planning, architecture.

Recibido: diciembre $3 / 2020$ Evaluado: mayo $20 / 202$ : Aceptado: mayo 25 / 2021

* El presente texto fue publicado originalmente en francés bajo el título "Métamorphoses éditoriales et construction d'un classique. Jean Castex, Jean-Charles Depaule, Philippe Pannerai, Formes urbaines: de l'îlot à la barre, como capítulo en: Chabard, P., y Kourniati, M. (dirs.) (2013). Raisons d'écrire. Livres d'architectes, 1945-1999. Paris: Éditions de La Villette. [Nota de los traductores] 


\section{Introducción}

Publicado en 1977, aunque escrito entre 1974 y 1975 bajo la forma de un informe de investigación, De l'îlot à la barre1 [De la manzana al bloque] ha sido reeditado y reimpreso repetidas veces desde entonces, tanto en Francia como en diversos países del mundo2. En los siete idiomas a los cuales ha sido traducido, el libro es conocido con algún título ligeramente adaptado a cada contexto local: Isolato urbano e citta contemporanea3 para los italianos; De rationele stad: van bouwblok tot wooneenheid4 en los Países Bajos, o Urban Forms: the Death and Life of the Urban Block5 en la tierra de Jane Jacobs.

El éxito de este libro cuyo estatus híbrido abraza por igual los campos de la investigación, de la enseñanza y de la práctica arquitectónica y urbana, se apoya en gran medida en la claridad de su argumentación, explícita ya en su título-eslogan y resumida sin ambages desde la primera frase:

Si el presente estudio debiera calificarse con una palabra, seguramente esta sería: agonía. La agonía de una organización espacial determinada: el îlot [la manzana], característico de la ciudad europea clásica que el siglo XIX transformó, y que el siglo XX ha abolido. (Panerai, 1975, 3)

Retomando a su manera la acusación -tan recurrente en la época- de los excesos propios del urbanismo modernista, De lîlot à la barre presentaba en su cubierta original otro documento de síntesis ${ }^{6}$ : se trata de un dibujo del arquitecto alemán Ernst May publicado en 1930 en la revista Das neue Frankfurt, y que muestra las cuatro etapas de la evolución urbana, desde la manzana tradicional hasta el bloque de viviendas que el propio May preconizaba. Dicho dibujo, entendido como una prueba de la voluntad deliberada de los "Modernos" para desmantelar las formas tradicionales de la ciudad, sirve paradójicamente para ilustrar la demostración del libro, concediéndole la precisión de un boceto.

Paralelamente a su función polémica, De l'îlot à la barre ha desempeñado también una función generacional: aún hoy, es un libro que encarna los ideales de una generación de arquitectos que se desmarcó colectivamente tras lo acontecido en Mayo de 1968, en un momento en el cual se generó algo más que una profunda ruptura,

1 En adelante se utiliza simplemente De l'îlot à la barre, para hacer referencia al libro en cuestión, tal y como lo hace el autor en el texto original en francés. [Nota de los traductores].

2 Ver el listado de ediciones y traducciones, al final del presente artículo.

3 En español podría traducirse como: "Manzana urbana y ciudad contemporánea".

4 En español podría traducirse como: "La ciudad racional: del bloque urbano al bloque de habitación".

5 En español podría traducirse como: "Muerte y vida de la manzana urbana".

6 En la edición de 1997, el dibujo presentado corresponde a un experimento gráfico titulado "Homenaje a Ernst May", con el cual se buscaba exacerbar su carácter. dando inicio a un periodo de transición en el medio arquitectónico. Desde mediados de los años 1960 hasta principios de los años 1980, se produjo una renovación de las élites y del marco institucional de la arquitectura francesa, así como también se veían cuestionadas las doctrinas vigentes en la profesión ${ }^{7}$. Aquellas doctrinas generalmente asociadas a De l'îlot à la barre, entre las cuales sobresalían la arquitectura urbana, la patrimonialización de los centros históricos, la residencialización de los grands ensembles, y el proyecto urbano, pasaron de ser minoritarias y emergentes, a dominar el panorama del urbanismo. Este giro progresivo en las relaciones de fuerza es explicable en gran medida por el éxito alcanzado por el libro, pero plantea interrogantes sobre las razones de su longevidad editorial y la evolución de sus usos. Si bien, De l'îlot à la barre fue reconocido inmediatamente como un "libro de referencia", "discreto y útil en medio del fracaso de la arquitectura" (Edelmann, 1978), es cierto también que al día de hoy este libro ha perdido buena parte de su carácter subversivo y pareciera estar congelado en su rol de "clásico".

Pero no es precisamente en su papel de "clásico" que analizamos De l'îlot à la barre en el presente texto: este ilustre estatus justifica a menudo una lectura antihistórica ${ }^{8}$ al presuponer a priori que el texto adquiere sentido en una época distinta a la suya. En lugar de actualizarlo o de "modelizar" su lectura para extraer enseñanzas útiles en el presente, nos parece pertinente abordarlo aquí como el producto de una época muy precisa en la cual los arquitectos reflexionaron sobre la ciudad: reflexiones que fueron formuladas en este libro mejor que en ninguna otra parte. Como también nos parece importante conocer los principales contextos de su recepción, con lo cual se evoca de paso, la vida de sus autores, las de otros personajes, y las historias de escuelas y de instituciones del medio arquitectónico.

\section{Archipiélago}

De l'îlot à la barre es un libro que se posiciona antes que nada sobre un frente intelectual. Su redacción fue financiada a partir de julio de 1974 por el Comité d'Orientation pour la Recherche et le Développement de l'Architecture -COR$\mathrm{DA}^{10}$, en el marco de su primera convocatoria

7 Ver los dos libros de Jean-Louis Violeau : Les Architectes et Mai 68 (2005) y Les architectes et Mai 81 (2010) ; así como el relato de Panerai en forma de autobiografía intelectual, titulado "Les territoires de l'architecture : petit parcours de l'analyse urbaine" (2012).

8 Fue el caso del análisis epistemológico de De l'îlot à la barre realizado por Stéphane Hanrot (2002).

9 Ver el artículo de Alain Viala, titulado "Qu'est-ce qu'un classique?" (1992).

10 El CORDA fue creado en febrero de 1972 con el propósito de incitar y financiar un tipo de investigación autónoma en arquitectura, renovando simultáneamente las doctrinas arquitectónicas (investigación y desarrollo). Su creación respondió a las conclusiones del denominado informe Lich- 
de proyectos $^{11}$. Es importante precisar, que la creación del CORDA buscó responder en aquel momento a una de las principales reivindicaciones de la generación del 68: sentar las bases para el desarrollo de un tipo de investigación fundamental en arquitectura, como reacción radical a la manera en la cual hasta entonces se había pensado y enseñado la arquitectura en la École des Beaux-Arts. Ante el ingreso masivo de baby-boomers a la École des Beaux-Arts durante la década de los sesenta, el modelo pedagógico basado en el atelier se vio sumido en una crisis estructural. Dicha pedagogía, organizada en torno a la relación maestro/discípulo fue entonces criticada violentamente al ser considerada como "anquilosada", "arcaica", "corporativista", "elitista", "profesionalizante" y "anti-intelectual". Los jóvenes arquitectos decidieron tomar distancia tanto de sus predecesores como de su cultura y de sus modelos, y para ello trabajaron en la reivindicación de su propio estatus intelectual y establecieron puentes con el mundo universitario de otras disciplinas.

Aunque el cierre de la sección de arquitectura de la École des Beaux-Arts en diciembre de 1968 representó una ruptura institucional, la manera en la cual el medio arquitectónico se recompuso luego, estuvo ampliamente determinada por las redes urdidas en -y por- la propia École des Beaux-Arts. Cada atelier, marcado por sus ritos, su jerarquía y su folklore, formaba una pequeña comunidad que compartía en torno a un mismo "patrón" varios años de vida colectiva, y en la cual los lazos forjados perduraban incluso durante la vida profesional ${ }^{12}$. Precisamente de aquel entorno surgió la complicidad entre Philippe Panerai (1940 - ), procedente de la burguesía versallesa y formado en el prestigioso Lycée Hoche, y Jean Castex (1942 - ) procedente de un medio más modesto de los suburbios del norte de París, y originario del sur-occidente del país: complicidad nacida más precisamente en el atelier Arretche-Gromort, en el cual Panerai ingresó en 1959, mientras Castex lo haría en 1960. Los dos jóvenes alumnos se encontraron en el seno de uno de los ateliers más poblados de la École des Beaux-Arts (un total de casi trescientos estudiantes), dirigido por Louis Arretche ${ }^{13}$ (1905-

nerowicz, presentado en 1970 bajo el título La Recherche architecturale, en el cual se señalaban las inmensas lagunas existentes en torno al tema. Antes de la supresión del CORDA en 1979, este fue dirigido principalmente por Jean-Paul Lesterlin (1942-1979), financiando alrededor de 150 investigaciones, seleccionadas inicialmente de común acuerdo, y más tarde según los resultados de tres convocatorias abiertas (1974, 1976 y 1978).

11 En febrero de 1974, 180 proyectos de investigación fueron postulados en este marco. El jurado, compuesto entre otros por Joseph Rykwert, Manfredo Tafuri y Michel de Certeau, seleccionó 45 proyectos, entre los cuales figuraba el presentado por Castex, Depaule y Panerai.

12 Ver por ejemplo, el relato del arquitecto Antoine Stinco, titulado "Mes Beaux-Arts" (2012).

13 Sobre Arretche, ver: Louis Arretche architecte, 1905-1991
1991), un personaje ambivalente, docente a la vez autoritario y ecléctico, urbanista formalista pero sensible a la historia, y arquitecto sin mayores talentos pero hábil patrón de una reconocida agencia, hombre de negocios y de contactos. Aquel fue un atelier que concentró desde el punto de vista cuantitativo, un gran número de destacados alumnos, de los cuales un amplio espectro escogió desarrollar carreras intelectuales ${ }^{14}$.

La red creada por los antiguos alumnos de Arretche fue afectada por una gran ruptura: en 1966, unos treinta estudiantes contestatarios decidieron entrar en rebelión y crearon un atelier auto-gestionado paralelo al oficial. Para aquel nuevo "atelier Collégial" fue elegido como patrón, el joven Bernard Huet, antiguo alumno del propio atelier Arretche-Gromort y que había obtenido su diploma en $1962^{15}$. Huet, quien entonces ya era reconocido como un joven arquitecto brillante, culto y poseedor de una cierta influencia -a pesar de su edad y su relativamente poca experiencia-, jugó un rol clave durante la crisis institucional de Mayo de 1968. En definitiva, aquella escisión separó por largo tiempo a los "disidentes" de los "legitimistas": de un lado, aquellos que siguieron a Huet y que fundaron con él la Unité Pédagogique d'Architecture $\mathrm{n}^{\circ} 8$ (UP8 $\left.{ }^{16}\right)$; y por otro lado, aquellos que siguiendo el ejemplo de Panerai y de Castex permanecieron leales a Arretche, fundador de la Unité Pédagogique d'Architecture $\mathrm{n}^{\circ} 3$ (UP3) que se instaló finalmente en las petites écuries [pequeñas caballerizas] del castillo de Versailles durante el otoño de 1968.

\section{Insularidad}

En aquel contexto, el estatus de Panerai (diplomado en 1967) y de Castex (diplomado en 1968) resulta paradójico por diversos motivos. En un periodo de profundos antagonismos ideológicos, los dos jóvenes arquitectos se mantuvieron poco politizados: en medio de los vientos de renovación teórica, pedagógica e incluso epistemológica que guiaba a los arquitectos, Panerai y Castex se vincularon a una de las UP menos sediciosas, ubicada entre París y la provincia. Sin embargo, al ser considerados como unos "traidores" por parte de sus antiguos colegas -y ahora enemigos- del "atelier Collégial", su legitimidad fue abiertamente cuestionada en Versailles en

(Roze, 1997); y Louis Arretche (Amouroux, 2010).

14 Por ejemplo: Pierre Sady (quien se ocupó por largo tiempo de la rica biblioteca del atelier), Bernard Huet (ingresó en 1950), Serge Santelli (1961), Philippe Duböy (1961), François Laisney (1962), Françoise Véry (1964), Georges Teyssot (1964), Bruno Fortier (1965), Phiippe Gresset (1965), Christian Moley (1965), Jacques Lucan (1965), etc.

15 Luego de obtener su diploma, Bernard Huet (1932-2001) continuó su formación en el extranjero: en el Politecnico di Milano en 1960-61, en la University of Pennsylvania en 1963-64, y en The University of Tokyo en 1964.

16 Ancestro de la actual École d'Architecture de Paris-Belleville. 
donde rivalizaban con importantes "antiguos" como Richard Helmy ex-asistente de Eugène Baudouin, pero sobre todo con Henri Bourdon uno de los discípulos más experimentados de Arretche. Y aunque sentían la necesidad de alejarse de la sombra de su patrón de atelier, Panerai y Castex no rechazaron sin embargo de forma radical la posibilidad de trabajar para Arretche, quien ocasionalmente les ofrecía trabajos específicos $^{17}$. Las condiciones confusas y ambiguas en las cuales los dos compañeros comenzaron en el invierno de 1969 su carrera de docente en el seno de la UP3, parecieron garantizarles paradójicamente, una situación de extrema y fecunda libertad por cuanto pudieron construir un pensamiento propio, a una prudente distancia de las modas de la época (estructuralismo, marxismo, semiología, etc.), y dieron forma a su propio espacio manteniéndolo a salvo de los grandes anatemas políticos e ideológicos.

Las reflexiones sobre la manzana, sobre la articulación entre las formas arquitectónicas y urbanas, y sobre su inteligibilidad, obsesionaban a Panerai y Castex desde mediados de los años 1960: es en esa dirección en la cual desplegaron sus investigaciones y su práctica pedagógica al interior de la UP ${ }^{18}$. Para afirmar su posición, los dos deciden fundar en 1973 la Association pour le Développement de la Recherche sur les Organisations Spatiales - ADROS, una asociación simple con sede en el propio domicilio de Panerai, que de alguna manera les garantizaba un marco colectivo, reconocible institucionalmente y susceptible de recibir financiación para proyectos -como por ejemplo, del CORDA-. En el plano teórico, los dos jóvenes investigadores se apoyaron en un corpus de referencias ampliamente renovado: organizaron numerosos viajes de estudio -en los cuales recolectaron el grueso de la documentación para De l'îlot à la barre-, importaban textos de otras regiones del planeta (Estados Unidos, Italia, etc.), y de otras disciplinas (ciencias humanas). Se aliaron también con otros jóvenes docentes: esto ocurrió a partir de 1969 con Jean-Charles Depaule (Toulon, 1945 - ), un egresado de la Sorbonne en 1967 (DES en Filosofía $\left.{ }^{19}\right)$, reacio a continuar con una carrera convencional como catedrático, con lo cual terminaría acercándose al medio arquitectónico

17 En 1967, Panerai trabajó en dos ocasiones durante tres meses en la agencia de Arretche, participando en el proyecto para el concurso de Halles de Paris. También gracias a Arretche, Panerai y Castex hacen por subcontrato para la APUR uno de los estudios sobre "tejidos urbanos constituidos", más precisamente, el del nororiente de París, en 1971.

18 Castex llegó a la UP3, en donde ya estaba Panerai, solamente tras su viaje a Estados Unidos entre marzo de 1968 y marzo de 1969. Allí, Castex trabajó con Roger Katan, uno de los protagonistas del Advocacy Planning en New York.

19 En 1967 presentó un trabajo sobre Jean-Jacques Rousseau, bajo la dirección de Henri Gouhier, luego de haber asistido regularmente al seminario que Louis Althusser impartía sobre Rousseau, en la École Normale Supérieure de Paris. por intermedio del sociólogo Henri Raymond ${ }^{20}$, de quien se convirtió en ferviente discípulo y colaborador $^{21}$. Depaule trajo al nuevo grupo la sociología profesada por Henri Lefebvre ${ }^{22}$-primero en Nanterre, y después de 1968 en Paris IX Dauphine en el Institut d'Urbanisme-, la cual se convertiría entonces gracias a la acción de figuras como Raymond, en uno de los campos privilegiados de diálogo entre las ciencias sociales y la arquitectura, e incluso entre los mismos arquitectos -como sucedió en la UP3 con Castex y Panerai ${ }^{23}$ o en la UP8 con Bernard Huet, Jean-Patrick Fortin o Claude Vié-. Aquella sociología ${ }^{24}$, tan progresista y avanzada para el análisis crítico de los grands ensembles, se hizo presente en la estructura teórica de De lî́lot à la barre. El deseo de reflexionar simultáneamente sobre las prácticas sociales y espaciales era evidente en el proyecto de investigación que Panerai quien figuró como director de la investigación-, Castex, Depaule y algunos de sus estudiantes ${ }^{25}$ presentaron al CORDA en 1974 bajo el título "Évolution comparée des modèles architecturaux et des modèles culturels dans la ville industrielle d'Haussmann à Le Corbusier".

El resultado final de dicha investigación, De l'îlot à la barre, puede ser leído como un trabajo de auto-legitimación de un grupo de jóvenes docentes, todos ellos poseedores aun de un estatus precario ${ }^{26}$ en el seno del competido panorama francés de la enseñanza de la arquitectura. La finalidad de aquella investigación fue sin duda pedagógica: se buscaba fundar con ella el campo mismo de sus futuras investigaciones, para así comenzar a alimentarlo; pero al mismo tiempo se pretendía con ella oponer un estatus de docente-investigador al tradicional estatus de

20 El sociólogo Henri Raymond, discípulo -pero rival- de Henri Lefebvre, dictó cursos de sociología urbana en el atelier Arretche a partir de 1966. Raymond fue miembro de la Commission de réforme de l'enseignement de l'architecture en 1968, y fundó la UP8 junto a Bernard Huet. Los seminarios que organizó en los años 1970 (en Oliva, Cogolin, etc.) fueron espacios importantes para la gestación de la investigación arquitectónica y urbana. Ver el libro que contiene las entrevistas realizadas por Jean-Pierre Frey (2006).

21 Especialmente en el seno del Institut de Sociologie Urbaine ISU, y del Centre de Recherche d'Architecture, d'Urbanisme et de Construction - RAUC, a principios de 1970.

22 Depaule preparaba desde 1967, bajo la dirección de Henri Lefebvre, la tesis titulada Les sauvages de l'architecture.

23 Castex y Panerai frecuentaron el seminario de Lefebvre desde el periodo 1965-1966. Panerai sustentó un trabajo colectivo de grado en 1969, en el Institut d'Urbanisme de Dauphine -en donde Lefebvre enseñó a partir de 1968-, titulado Structures urbaines et villageoises dans le Haut-Rouergue, analyse typologique de 12 agglomérations.

24 A través de los trabajos de Bernard y Nicole Haumont, Raymond Ledrut, Henri Raymond, y Marion Segaud

25 Especialmente Michel Veyrenche, quien aparece como co-autor de la primera parte del volumen, así como también Denis Farge y Dominique Hubert por las ilustraciones.

26 Solo hasta 1977, Panerai obtuvo un puesto como docente de tiempo completo (P1), más exactamente aquel que dejó Henri Bourdon, quien murió un año antes. 
patrón de atelier -es decir, al de docente-practicante encarnado por Louis Arretche-.

\section{Terrenos}

El informe final de la investigación, entregado en 1975, comprende dos volúmenes relativamente independientes. El primero de ellos, titulado Principes d'analyse urbaine ${ }^{27}$ [Principios de análisis urbano] sobresalía por su naturaleza teórica y metodológica, la cual daba forma a la futura "caja de herramientas" del ADROS. El segundo volumen, titulado De l'îlot à la barre: contribution à une définition de l'architecture urbaine articulaba por sí solo varios fragmentos.

La primera parte, firmada inicialmente por Jean Castex, Philippe Panerai y Michel Veyrenche ${ }^{28}$, se compone de "cinco ejemplos históri$\cos ^{\prime \prime}$ presentados cronológicamente (de los años 1850 a los años 1960) como estudios de caso que en su conjunto ponen en evidencia "la evolución de los modelos arquitectónicos" anunciada en el título general de la investigación: una evolución que conduciría al estallido progresivo de la aglomeración de las ciudades. Una segunda parte de treinta páginas, escrita por Panerai y titulada "Élaboration et transmission des modèles architecturaux", constituye casi un capítulo de síntesis en donde se intenta inscribir los cinco estudios de caso presentados, dentro de una reflexión general que podría describirse como una cartografía de filiaciones mutuas de los cinco ejemplos, todo ello en el marco de una historia de las ideas arquitectónicas. Una tercera parte de tan solo diez páginas, escrita por Depaule y titulada "Les avatars de l'îlot et la pratique de l'espace", aparece como un texto más independiente en el cual se busca articular el análisis morfológico de la manzana con el análisis social y antropológico de los usos que se despliegan en su interior: este corto capítulo que arroja muchos más interrogantes de los que él mismo responde, no es tanto un análisis sino más bien el esbozo de una problemática de investigación que ocupará la carrera posterior de Depaule.

La primera parte del libro, con una extensión de ciento cincuenta páginas, constituye el cuerpo principal con la sucesión de ejemplos analizados: la manzana haussmaniana ${ }^{29}$; el close ${ }^{30}$ inglés típico de las garden cities de los

27 Este volumen fue publicado posteriormente citando los autores de dos maneras: Éléments d'analyse urbaine (Demorgon, Depaule, Panerai, Veyrenche, 1980); y más tarde: Analyse urbaine (Demorgon, Depaule, Panerai, 1999).

28 El nombre de Michel Veyrenche desaparece definitivamente en las ediciones posteriores de De l'îlot à la barre.

29 Considerada la principal contribución de Castex a la investigación.

30 Pequeño conjunto de casas (medianeras o no) dispuestas entorno de un jardín o de un patio común, con jardines privados en la parte posterior. El close no es sino una forma entre tantas otras perfeccionadas por Unwin el village green, el quadrangle, el cul-de-sac, etc.) años 1910-1920; las manzanas de Amsterdam ${ }^{31}$ características de los suburbios del sur de la ciudad planificados por Hendrick Berlage en los años 1915-1917; la Siedlung que bajo diversas formas encarna el Neue Frankfurt de Ernst May ${ }^{32}$ en los años 1920-1930; y por último, la unidad habitacional imaginada por Le Corbusier, especie de "manzana vertical" elevada con respecto al suelo gracias a los pilotis, de la cual Panerai y Castex incluyen cuatro realizaciones de posguerra: Marseille, Nantes, Briey y Firminy ${ }^{33}$ (1975, 154-157).

¿Cuál vínculo -diferente al retórico- conecta estos casos en el tiempo y en el espacio? En 1975, Panerai explicaba en el prólogo la selección de dicho corpus según un criterio simple: "formas de urbanización [...] en donde el control de la operación estaba asegurada por un autoridad única, ya sea pública o semi-pública, actuando sobre una escala bastante amplia como para pretender un control efectivo del espacio urbano" $(1975,5)$. Más tarde, en el prólogo a la edición de 1997, Panerai relativizaba el rigor de dicha selección, reconociendo que había "tenido algo de arbitraria, como consecuencia de los intereses de los autores de De l'îlot à la barre, y del material del cual disponían en aquel momento" $(1997,12)$.

De hecho, el corpus resulta bastante coyuntural: trabajar sobre la manzana "haussmaniana" tuvo que ver con una tendencia -bastante común en aquella generación- de revalorización del París del siglo XIX; como podría verse también allí una finalidad urbanística, en un momento en que el APUR34 dirigido por Pierre-Yves Ligen y controlado por Louis Arretche se ocupaba de la reflexión sobre el nuevo plan de ocupación de suelos de París -adoptado finalmente en 1977-. Desde los años 1960, tanto las garden cities de Raymond Unwin, como el París de Haussmann, y el Amsterdam Zuid de Berlage fueron las referencias recurrentes en la revista italiana Casabella-Continuità -dirigida por Ernesto Nathan Rogers- bajo la pluma de Carlo Aymonino o de Aldo Rossi (cuyos cursos en Zúrich fueron seguidos por camaradas de Panerai y de Castex como Xavier Fabre, Benoît Carrie y Thierry Roze35).

31 Conjunto alineado sobre la vía, a menudo diseñado por un solo arquitecto, encerrando casi siempre un gran espacio verde público, con lo cual modifica el estatus interno de la manzana.

32 Arquitecto representativo del Movimiento Moderno, Ernst May ocupó las funciones de Stadtbaurat (urbanista y arquitecto en jefe) de Frankfurt entre 1925 y 1930.

33 Omiten sin embargo el proyecto realizado en Berlin-Charlottenburg (1955-1958).

34 El Atelier Parisien d'Urbanisme - APUR fue fundado en 1967 por el Conseil Municipal de Paris. En 1982, François Loyer realizó un extenso trabajo sobre el tejido haussmaniano, importante contribución para la rehabilitación del parís del siglo XIX. Ver especialmente Paris XIXe siècle: I'immeuble et la rue (Loyer, 1987).

35 Autor de un trabajo sobre la Neue Frankfurt. Ver especialmente: Ernst May, Frankfurter Siedlungen (Roze, 1973). 
Del periodo de principios de los años 1970, pueden citarse igualmente los trabajos sobre el Neue Frankfurt de Ernst May, realizados por Manfredo Tafuri (1971) y por Giorgio Grassi $(1975,1983)$.

Surge la pregunta del porqué el equipo de la ADROS no eligió para los ejemplos estudiados, únicamente casos franceses: las manzanas abiertas teorizadas por Adolphe Augustin-Rey en los años 1900, las Habitations à Bon Marché del París de principios de siglo, o incluso las cités-jardins del periodo de entreguerras, hubieran todos ellos tenido un valor equivalente al de los ejemplos "extranjeros" finalmente usados en De l'îlot à la barre. Criticado por el propio CORDA36, esta preferencia por casos "no franceses" puede comprenderse bajo la perspectiva en aquel momento de la competencia implícita entre ex-colegas de la desaparecida École des Beaux-Arts, y particularmente del atelier Arretche: al explorar temáticas de investigación similares -la lectura morfológica de la arquitectura y de la ciudad-abordadas bajo la óptica de una cultura común -la tipo-morfologia italiana, la sociología lefebvriana-, lo que distinguiría verdaderamente las realizaciones de los diferentes equipos de investigación -siempre al tanto de los respectivos trabajos de otros equipos-, serían sus campos de estudio. La ADROS estudiaba los closes ingleses y las Siedlungen alemanas, en el momento en que la Italia barroca era explorada por el Institut d'Études et de Recherches Architecturales et Urbaines - IERAU37 (asociación fundada por Bernard Huet en 1971); y luego, cuando los análisis de unos tratan sobre las manzanas del Amsterdam-Zuid, los otros se ocupan de las Habitations à Bon Marché parisinas38. En el cuarto número de los Cahiers de la recherche architecturale, los trabajos de la ADROS sobre Versailles $(1979,63-78)$ fueron publicados junto a los estudios de la IERAU sobre Nancy (1979, 79-87), dos ejemplos de urbanismo clásico.

Esta territorialización que se daba en torno a los objetos de investigación, y que en el fondo ocultaba una gran complicidad intelectual, permitía encarrilar de manera específica trayectorias personales o de equipos, tal y como lo reconoce Panerai: "mi bronca con Huet, es lo mejor que me ha sucedido39!". Pero dicha competencia, o mejor, dicha emulación intelectual, se refle-

36 Se trata de Claude Soucy, del CORDA, quien estimaba que hacían falta más ejemplos franceses, y sugirió al equipo de ADROS agregar el estudio de caso sobre las "unidades de habitación" de Le Corbusier que no figuraba en la propuesta inicial a la convocatoria de 1974.

37 Ver especialmente : Urbanistique et société baroques (Dufour, Huet \& Raymond, 1977).

38 Ver especialmente: "Les HBM et la ceinture de Paris" (Chiffard \& Delorme, 1977). Esta investigación fue financiada en el marco de la misma convocatoria del CORDA que en 1974 dio origen a De l'îlot à la barre.

39 Entrevista realizada en París a Panerai por Pierre Chabard, el 27 de noviembre de 2008 jaba también en los contenidos teóricos de las investigaciones, con notables matices en torno a las perspectivas que alimentaban los principales debates de la época.

Observemos a continuación cómo De l'îlot à la barre se posicionó de forma bastante original frente a tres de las cuestiones fundamentales debatidas entonces: la lectura de la ciudad, la tipo-morfología y la arquitectura urbana.

\section{Textura}

Para la ADROS, "la manzana se impone como el resultado [...] de una lectura" y de forma general, la ciudad es considerada a priori como una "organización espacial" inteligible (1975, 205). Esta predilección por las categorías formales y espaciales refleja antes que nada un interés por la indagación en torno a la autonomía y a la especificidad disciplinar de la arquitectura:

El espacio físico es justiciable de análisis objetivos que permiten alcanzar un primer nivel de significado: dicho nivel es exclusivo de la arquitectura y puede potencialmente formar una base estable sobre la cual vendrían a articularse otros contenidos accesibles desde otras lecturas [...] Un enfoque como este es aplicable al espacio urbano, es decir, que entre tantas lecturas posibles, se abordará la ciudad como una arquitectura, como una configuración espacial que debe ser descompuesta en elementos menores para así entender las diferencias presentes allí. (Panerai, 1975,4$)$

El principal desafío para los autores consistía en definir las herramientas, y en encontrar un método adecuado para facilitarle al arquitecto la tarea de descifrar la forma urbana, de poder leer la "textura" de la ciudad, en pocas palabras: de extraer de una lectura morfológica, un significado o un discurso científico. Para diferenciarse de otro tipo de intelectuales -de aquellos que leen libros-, los arquitectos debieran ser aqueIlos capaces de leer las ciudades: "ello explicaría que así como construimos una bibliografía, hemos elaborado también en un anexo a la investigación las referencias de todos aquellos lugares visitados durante esta, y que han nutrido la reflexión" (Panerai, 1975, 4).

El problema del desciframiento de las estructuras espaciales de la ciudad flotaba entonces en el ambiente, incluso más allá del entorno de los arquitectos. Hacia principios de los años 1970, diversas disciplinas como la sociología ${ }^{40}$, la semiología y la filosofía ${ }^{41}$ se interesaron especial-

40 Ver al respecto los trabajos del sociólogo Henri Raymond sobre el espacio arquitectónico. Entre ellos, la investigación titulada Analyse de l'espace architectural, financiada por la DGRST y publicada en febrero de 1970.

41 Sin duda, marca un hito la conferencia dictada el 14 de marzo de 1967 por M. Foucault (en el Centre d'Études Architecturales fundado en 1951 por Auguste Perret), en la cual aborda el tema de las heterotopías. Fue 
mente por el objeto arquitectónico y/o urbano, estimulando nuevas investigaciones por parte de los arquitectos: todo ello como síntoma de un spatial turn, o en todo caso de una clara predilección de las ciencias humanas de la posguerra por el concepto de espacio en detrimento del interés prestado al concepto de tiempo. El contenido del número de L'Architecture d'aujourd'hui de diciembre de 1970 que incluía un artículo escrito por Roland Barthes, estaba dominado por textos de claro enfoque lingüístico y estructuralista sobre "la ciudad", tal y como lo demuestran las "observaciones a propósito de la semiología urbana" realizadas por Françoise Choay, quien retomando el argumento de su célebre texto de 1969 sobre los "espacements" [intervalos] oponía por ejemplo, el espacio clásico "de predominio metafórico" al "espacio medieval de claro predominio metonímico ${ }^{42 " .}$

En dicho número, el artículo de Castex y Panerai titulado "Notes sur la structure de l'espace urbain" (1970, 30-33) no sobresalía a primera vista. Y sin embargo, su vocabulario simple y directo que rompía con el argot semiologizante del momento, sumado a su rigor lógico casi naif y su "sentido común" mucho más intuitivo que teórico, hacían de este un texto singular que anunciaba ya el tono presente más tarde en De l'îlot à la barre. Para los autores, su "lectura" de la ciudad se nutría de un reducido número de referencias teóricas a las cuales seguirían siendo fieles: algunas experiencias arquitectónicas anglosajonas de análisis estructural de la ciudad43, o la sociología urbana de Lefebvre con la cual el propio Castex reconoce su deuda:

Con el propósito de abordar la ciudad de manera objetiva en su célebre Droit à la ville de 1967, Henri Lefebvre había decidido estudiar la forma física de la ciudad para así leerla como un texto que permitiera comprender el contexto, es decir, la realidad social [...] Se fundaba así una "ciencia de la ciudad", y con ello se fijaban claramente el campo y las implicaciones del análisis urbano, por cuanto "la ciudad, variable [...] arquitectónica" se articulaba con "lo urbano" como si se tratara de un lenguaje. (Castex, $1980,7)$

En ese contexto general, puede decirse que el enfoque de Castex y Panerai fue desde su origen, más estructuralista que semiológico. Su lectura de la ciudad apuntaba menos a la presentación de un significado que a la revelación de un lenguaje espacial, y menos a la ostentación de una

difundida apenas en 1984 en las páginas de la revista Architecture-Mouvement-Continuité-AMC

42 Ver también el artículo de Choay titulado "Remarques à propos de sémiologie urbaine", publicado en L'Architecture d'aujourd'hui (1970, 9).

43 Especialmente aquellas de Gordon Cullen (noción de townscape), de Kevin Lynch (nociones de legibility o de imageability), y de Christopher Alexander (noción de pattern). teoría del signo que a la exposición de una simple "sintaxis" -término que los autores usaron durante un tiempo como su bandera44-. Hastiados rápidamente por la moda semiológica, Castex y Panerai adoptaron en breve un enfoque sistemático y tipológico, mucho menos arraigado en las ciencias humanas de su tiempo, de lo que podía estarlo en la tradición enciclopédica de la llustración. Depaule citaba incluso una cita tomada de Essai sur l'origine des langues de J.-J. Rousseau, que por aquel entonces tenía como costumbre repetir45: "Es necesario observar las diferencias para descubrir las propiedades" (1781, s.p).

\section{Tipos}

Más cercano a la fe positivista de Bouvard y de Pécuchet que de los conceptos etéreos de la French Theory postmoderna, y más cercano a la historia de las ciudades de Pierre Lavedan ${ }^{46}$ o de Robert Auzelle ${ }^{47}$ que de Aldo Rossi, el gusto exhibido por Castex y Panerai hacia la clasificación y la taxonomía de las formas los hacía diferentes dentro del escenario más importante de la época: el de la tipo-morfología. Los antecedentes italianos de la tipo-morfología que habían anticipado en algunos años a las tentativas francesas de fundar una investigación exclusivamente arquitectónica $^{48}$, ya habían sido identificados plenamente por Bernard Huet hacia finales de $1960^{49}$, para ser luego tomados por la generación que arribaba (Georges Teyssot, Philippe Duboÿ, Pierre Pinon, François Laisney, etc.). Aquella reflexión sobre la ciudad, teorizada por Carlo Aymonino y Aldo Rossi en el Istituto Universitario di Architettura di Venezia - IUAV, postulaba una dialéctica -que no era necesariamente causal- entre dos tipos de lectura que tenían una larga ascendencia: el análisis morfológico del espacio urbano (morfologia urbana) y la clasificación tipológica de las estructuras construidas (tipologia edilizia ${ }^{50}$ ).

44 Antes de la creación del ADROS, Castex y Panerai escribieron algunos artículos bajo el nombre de Groupe Syntaxe, entre ellos: "Autopsie d'un village, Marcillac" en L'Architecture d'aujourd'hui (1972); y "Parti pris" en Architecture-Mouvement-Continuité - AMC (1974). El Groupe Syntaxe federaba algunos de los primeros estudiantes de la UP3, como Patrick Céleste, Michel Raynaud, y Philippe Gresset.

45 Entrevista realizada en París a Panerai por Pierre Chabard, el 12 de noviembre de 2008.

46 Ver las diferentes versiones editoriales de l'Histoire de l'urbanisme de Pierre Lavedan. Sobre dicho libro y su autor, ver también la teis doctoral de Isabelle Grudet titulada L'Histoire de l'urbanisme de Pierre Lavedan, 1919-1955. Entre savoir et action (2005).

47 Panerai reconoce haber descubierto tardíamente el trabajo de Robert Auzelle y de Ivan Jankovic $(2012,357)$, publicado entre 1947 y 1967 en 31 fascículos: se trata de la Encyclopédie de l'urbanisme.

48 Ver el estudio de Pier Giorgio Gerosa titulado "La ville comme artefact. La question typologique et la morphologie" (1991, 177-252).

49 Ver especialmente el trabajo de Jean-Louis Cohen titulado La coupure entre architectes et intellectuels, ou les enseignements de l'italophilie (1984).

$50 \mathrm{Al}$ respecto, ver: Contributo al problema dei rapporti tra tipologia edilizia e morfologia urbana (Rossi, 1964); Aspetti e 
Interesados principalmente por Aymonino, más que por Rossi, Castex y Panerai mantuvieron una conexión ambigua con este campo. Mientras que Ahmet Gülgönen y François Laisney anunciaron explícitamente su filiación italiana en el título del informe de investigación presentado en la convocatoria del CORDA: Morphologie urbaine et typologie architecturale (1977). Por su parte, Castex y Panerai se referían al tema de una manera más distanciada e incluso crítica. Aymonino y Rossi son citados muy pocas veces en De I'îlot à la barre, y cuando aparecen, lo hacen casi siempre para evocar o explicar aspectos históricos antes que para señalar aspectos tipo-morfológicos de sus investigaciones. En el segundo volumen de la investigación, Aymonino y Rossi son presentados como los discípulos de Saverio Muratori, autor de Studi per une operante storia urbana di Venezia (1960) y hasta entonces desconocido en Francia, "descubierto" coincidencialmente por Castex en 1969. Muratori fue para Castex y Panerai, una referencia alternativa, anterior a Aymonino y Rossi, dos de los profesores vedettes en la IUAV.

En el verano de 1978, seis meses antes de que la editorial DUNOD publicara por primera vez De l'îlot à la barre, Panerai aclaraba su posición en un artículo que causó revuelo, titulado simplemente "Typologies" (1979): en él, desestimaba la "utilización casi mágica del binomio morfo-tipo para conjurar el sortilegio presente en tantos estudios recientes", dejando a un lado los trabajos de Rossi sobre el "tipo ${ }^{51 "}$ e identificando las raíces directas de dicha noción en la teoría arquitectónica neoclásica (Jean-Nicolas-Louis Durand, Quatremère de Quincy). Al invocar el "conocimiento italiano", Panerai hace eco de las críticas realizadas por Tafuri a Aymonino y a Rossi, juzgando sus investigaciones como "equívocas" (1976, 103). En el mismo artículo, Panerai critica la noción de "morfología urbana", tan connotada para su gusto, como también la noción misma de "tipología": para reemplazar la primera de ellas, Panerai prefiere las nociones de "estructura urbana" o de "forma urbana" (que será justamente el título del libro publicado por DUNOD); mientras que para la segunda noción, la conceptualiza a su manera apropiándose un poco del mencionado "conocimiento italiano" aunque alejándose del uso dado por sus seguidores franceses, como sucedía entonces con Christian Devillers (a cuyo artículo respondía implícitamente Panerai ${ }^{52}$ ) y con los investigadores del IERAU ${ }^{53}$.

problemi della tipologia edilizia (Aymonino \& al., 1964); La formazione dell concetto di tipologia edilizia (Aymonino \& Rossi, 1965).

51 Especialmente en L'architettura della città (1966), traducida y publicada en 1981 por Éditions de L'Équerre.

52 Ver el artículo de Devillers titulado "Typologie de I'habitat et morphologie urbaine" (L'Architecture d'aujourd'hui (1974).

53 Ver el análisis de Depaule acerca de las diferentes definicio-
En De l'îlot à la barre se aprecian también dos diferencias con respecto a la noción de tipo-morfologia. La primera de ellas tiene que ver con la decisión de Panerai y Castex de trabajar sobre formas urbanas hiper-planificadas en las cuales es posible eventualmente identificar un autor único, y en donde la arquitectura puede aparecer no como un efecto, sino como una causa. De manera opuesta, la mayor parte de los trabajos italianos, desde aquellos de Muratori sobre Venecia, hasta aquellos de otros autores sobre Padova $^{54}$, los cuales estudiaban urbanizaciones y arquitecturas "menores ${ }^{55}$ ", es decir, objetos de estudio en los cuales su único autor había cumplido al mismo tiempo el rol de tipo-morfólogo.

La segunda diferencia se manifiesta en el empleo parsimonioso de la noción de "tipología" a la cual Panerai prefiere anteponer aquella de "modelo" que él mismo teoriza en el sexto capítulo: Panerai encuentra en la "elaboración y transmisión de modelos arquitectónicos" aquel vínculo invisible existente entre los cinco ejemplos expuestos en el libro. Por ejemplo, en el caso del close de Raymon Unwin, no se trata obviamente de un "tipo" ya que su uso se redujo a unas cuantas garden cities, extrañas excepciones en el universo de la urbanización londinense; pero en cambio como lo intenta demostrar Panerai, el close podría ser un "modelo" que incidió de manera más o menos consciente en los proyectos de Hendrik Berlage o de Ernst May. La cultura arquitectónica se consolida así como espacio de la circulación y la readaptación perpetua de tales "modelos". Este concepto que fue realmente tomado en préstamo del discurso de Lefebvre, puede ser leído de igual forma como una versión erudita del "tubard"56", herramienta fundamental para la enseñanza del proyecto impartida en la École des Beaux-Arts (particularmente en el atelier de Arretche) y cuya trazabilidad animaba las sesiones de los jurados invitados a evaluar los proyectos de atelier. Panerai reconoce en todo caso, la ardua tarea que implica el análisis de este juego permanente entre la influencia y la referencia en la concepción arquitectónica:

Estudio delicado, por cuanto los modelos arquitectónicos no se reducen a la exposición (cuando esta existe) de teorías explícitas de los arquitectos o de sus propias doctrinas: los modelos arquitectónicos constituyen esquemas por lo general inconscientes o inconfesados a partir

nes dadas a la tipología arquitectónica (1996, 28-30).

54 Ver, por ejemplo: La Città di Padova, saggio di analisi urbana (1966).

55 Ver especialmente: Trincanato, R. (1948). Venezia Minore. Milan: Edizioni del Milione.

56 Según la doctrina beauxartiana: modelo o fuente de inspiración formal que un buen arquitecto debe saber imitar de manera consciente y razonada en su proyecto. Ver: Patrick Céleste, "Vocabulaire traditionnel des dessins d'architectu$\mathrm{re}^{\prime \prime}$, en Jean Dethier (dir.), Images et imaginaires de I'architecture, Paris, Centre Georges Pompidou, 1984, p. 158. 
de los cuales se efectúa la puesta en forma de los proyectos [...] Estos modelos no son ajenos a las condiciones generales de cada época (el desarrollo industrial y sus consecuencias sobre la urbanización, el hábitat, los modos de vida) pero deben confrontarse con las condiciones económicas desde una posición de relativa autonomía. (Castex, Depaule, y Pannerai, 1975, 164)

Una vez más, la cuestión sobre la autonomía de la arquitectura entra en juego, ya no solamente como campo de investigación sino principalmente como práctica profesional específica capaz de renovar el urbanismo contemporáneo a través del uso consciente y erudito de sus propios modelos, es decir, por medio de la congruencia con los "tipos consagrados" e inherentes a una sociedad determinada. Este enfoque operativo de De l'îlot à la barre sitúa el libro de manera explícita, sobre un tercer frente de batalla: "la arquitectura urbana", aquella que desde el propio subtítulo, los autores pretenden ayudar a definir.

\section{Tramas}

En la Francia de los años 1970, la expresión "arquitectura urbana" era sinónimo de algo complejo y nebuloso: por un lado, expresaba una voluntad casi unánime por parte de los arquitectos de aquella generación, de renovar las calidades de la urbanidad de las ciudades antiguas; pero por otro lado, dicha expresión abarcaba posturas teóricas y prácticas muy diferentes e incluso contradictorias. En un extremo del espectro, los "morfólogos" -o "metodólogos" - reivindicaban una respuesta exclusivamente formal: la ciudad no era más que una gran arquitectura, y para que ella volviera a ser más "urbana" bastaba con reformar los métodos de composición de la misma arquitectura, con introducir la complejidad, la diferenciación y la indeterminación en su forma, con enriquecer cualidades como el policentrismo, la diversidad, la inconclusión, el crecimiento, la flexibilidad y la proliferación espontánea. Se hablaba entonces de sistemas urbanos, de tramas, de tejidos, de mallas, de redes. Este enfoque de la arquitectura urbana, apoyado en herramientas teóricas y científicas importadas desde las matemáticas, desde la geometría, y hasta desde la psicosociología de las formas, dominaba la producción arquitectónica y urbana de las villes nouvelles de principios de los años $1970^{57}$.

En el otro extremo del espectro estaban los "analistas", absortos en la hermenéutica de los tejidos de la ciudad antigua, buscando ante todo una respuesta en lo urbano tradicional. Es así como por ejemplo, en 1967 el equipo del historiador del arte André Chastel emprendió un

57 Ver los dos números consecutivos que la revista Techniques et architecture dedica a la arquitectura urbana, en octubre de $1975\left(n^{\circ} 306\right)$ y enero de $1976\left(n^{\circ} 307\right)$ minucioso análisis morfológico e histórico de la textura urbana del sector de Les Halles en el centro de París, predio por predio; publicado bajo el título Système de l'architecture urbaine (Boudon, Chastel, Cousy, \& Hamon, 1977). En este, la expresión "arquitectura urbana" es usada para designar no tanto una doctrina, como sí un objeto de estudio: se trata de una cierta manera de analizar la ciudad, articulando la escala arquitectónica con la escala urbana, y para lo cual la unidad de observación escogida era el predio, considerado como "el mínimo común denominador de lo urbano".

De l'îlot à la barre abría en aquel debate, una vía novedosa e intermedia. Castex y Panerai tomaban así distancia de los "juegos metodológico-estructuralistas" $(1997,11)$ que tanto habían Ilamado su atención a principios de los años $1970^{58}$ cuando se mostraban fascinados por experiencias como Habitat 67, el proyecto de súper-manzana concebido por Moshe Safdie y construido con motivo de la International and Universal Exposition realizada en Montreal en $1967^{59}$. Abogando por la "defensa de los modelos culturales de los habitantes, y por la indagación sobre la historia", y reivindicando que la complejidad de lo urbano no es reductible al proyecto arquitectónico, Castex y Panerai parecían situarse más cerca de los trabajos liderados por Chastel, aunque con un par de diferencias claras. La primera: Castex y Panerai consideraban la dialéctica entre ciudad y arquitectura, a la escala propia de la manzana y no a la escala del predio. La segunda: para ellos, la arquitectura urbana no se reducía simplemente a la construcción de un conocimiento: "Estudiar la manzana tradicional [...], no supone únicamente conocer la lógica de la ciudad antigua, o profundizar en este o en aquel capítulo de la historia de la arquitectura" $(1975,205)$; sino que implicaba la elaboración de una respuesta alternativa por parte del arquitecto al problema del urbanismo como "proyecto urbano". Visto desde esta perspectiva, el libro podría también haberse titulado: De la barre à l'îlot.

\section{Usos}

La originalidad de De l'îlot à la barre se inscribe cuidadosamente en los debates de la época. Pero, ¿cómo explicar que haya sobrevivido a aquellos? ¿Qué es exactamente aquello que diferencia el libro en sus sucesivas publicaciones [en 1975 por el CORDA, en 1977 por DUNOD ${ }^{60}$, y en 1997 por Parenthèses]?

\footnotetext{
58 Castex y Panerai presentaron dos proyectos de manzanas megaestructurales para el concurso de ideas de arquitectura y urbanismo realizado en Cannes en marzo de 1970, y para la intervención de la Alstadt en Karlsruhe en 1971. Ver al respecto el texto de Chaslin (1999).

59 Castex y Panerai obtuvieron una beca de viaje (por un mes) otorgada por la Grand Masse des Beaux-Arts, para visitar la Expo de Montreal de 1967.

60 Más exactamente en la colección "Aspects de l'urbanisme",
} 
La comparación sistemática de estas ediciones nos muestra una estabilidad, una permanencia del texto original. Entre las ediciones de CORDA y de DUNOD, no existen sino apenas unas sesenta modificaciones que van desde las más ínfimas (suprimir o agregar una palabra), hasta algunas más relevantes (agregar o reescribir un párrafo). En los cinco primeros capítulos (que corresponden a los cinco estudios de caso), las modificaciones fueron bastante sencillas y apuntaban esencialmente a volver más claro, más preciso y más eficaz, un texto que globalmente permanecía intacto.

Del total de modificaciones realizadas globalmente al texto, no menos de un cuarto de estas corresponden al capítulo de Jean-Charles Depaule, el cual ocupa sin embargo tan solo un $5 \%$ del libro: casi cada párrafo fue objeto de un nuevo desarrollo analítico, teórico o metodológico, enriqueciendo el texto pero al mismo tiempo matizándolo y haciéndolo más complejo. Mientras en el resto del libro, los otros autores se contentaron con afinar el discurso preexistente, Depaule profundiza y densifica una problemática de investigación personal que lo alejó gradualmente del ADROS y de la UP3 ${ }^{61}$. Asimismo, este capítulo fue objeto de la única modificación notable en el orden de la tabla de contenidos: el lugar de privilegio que inicialmente había ocupado al final del libro tuvo que ceder su espacio al capítulo de Panerai sobre la circulación de los modelos arquitectónicos. $Y$ así, mientras que en el informe de investigación entregado en 1975, el texto de Depaule asumía dentro de una falsa simetría, la réplica socio-antropológica a los análisis arquitectónicos y urbanos, en la nueva versión de 1977 pasaba a ser absorbido en el cuerpo del libro al ser puesto como entre paréntesis, en medio de los capítulos de los "cinco ejemplos" y el texto de Panerai, que pasaba así a adquirir un estatus concluyente.

Así, bajo un nuevo título más simple y sintético (Formes urbaines: de l'îlot à la barre) el libro era reorganizado para servir mejor a los intereses de sus autores con respecto a dos desafíos principales: la docencia y la investigación. Se trataba primero que todo, de asumir posiciones pedagógicas bien definidas en un momento en el cual eran anunciadas las grandes reformas profesionalizantes de las UP de principios de los años $1980^{62}$; y por otra parte, se debía asegurar la

dirigida por René Loué, y en la cual se publican entre 1969 y mediados de los años 1980, una veintena de textos de referencia: de Ebenezer Howard, Kevin Lynch, Christophe Alexander, Amos Rapoport y Robert Venturi, entre otros autores.

61 En 1987 ingresa al CNRS [Centre National de la Recherche Scientifique]. Entre 1988 y 1991 ocupa un cargo en el Cairo como investigador de la CNRS en el Centre d'études et de documentation économiques, juridiques et sociales.

62 Primera de una larga serie, la reforma de 1978 fue presentada como aquella del "retour de la planche à dessin" [el regreso de la mesa de dibujo]. Ver al respecto el estudio de Guy sostenibilidad de la ADROS en el momento en que comenzaban a estancarse los presupuestos disponibles para la investigación ${ }^{63}$.

Sin duda, tanto el libro como los propios autores habían recibido en aquel momento un apoyo generoso de las instituciones: el Centre d'Etudes et de la Recherche Architecturales - CERA ${ }^{64}$ financió la publicación de De l'îlot à la barre con la editorial DUNOD; y simultáneamente a dicha publicación en diciembre de 1977, dos de los capítulos son publicados en el primer número de Cahiers de la recherche architecturale, nueva revista producida por el propio CERA ${ }^{65}$ y consagrada justamente a los estudios sobre las formas urbanas. En 1978, la ADROS se institucionaliza y pasa a ser una formación de investigación habilitada, para luego ser oficialmente integrada en 1981 a la Ecole d'Architecture de Versailles. En 1986, la ADROS modificó su nombre aunque conservando su fonética, pasando a ser el reconocido Laboratoire de Recherche, Histoire Architecturale et Urbaine - Société - LADRHAUS.

La edición de 1997, veinte años más tarde, corresponde a un contexto muy diferente. La carrera de cada uno de los autores los había alejado profesionalmente entre sí. Jean-Charles Depaule, quien enseñó en Versailles hasta 1987, había continuado en el CNRS una carrera como investigador en antropología urbana, especializándose en el estudio del mundo árabe musulmán. Jean Castex había permanecido en la UP3 pero había orientado específicamente su carrera como docente-investigador en historia de la arquitectura: después de la publicación en 1990 de su célebre curso sobre arquitectura clásica titulado Renaissance, baroque et classicisme. Histoire de l'architecture, 1420-1720 (1990), Castex sustentó en 1997 la tesis doctoral François Mansart : étendue et marge du projet classique, realizada bajo la direccion de Françoise Choay. Por su parte, Philippe Panerai, tras haber sido uno de los pilares de la École d'Architecture de VersaiIles (habiendo dirigido el LADRHAUS entre 1986 y 1993), se había alejado radicalmente de esta para ir a ocupar la plaza dejada por Jean-Louis

Tapie titulado Les Architectes: mutations d'une profession (2000).

63 A partir de 1976-1977, el Estado se orientó hacia un tipo de investigación más operativa y realizada en el seno de los laboratorios habilitados para ello. El CORDA fue suprimido en 1979.

64 En reemplazo del Institut de l'Environnement, el CERA fue creado en enero de 1977 por la Direction de l'Architecture del Ministère des Affaires Culturelles, con el fin de coordinar todo lo relacionado con la investigación en el campo de la arquitectura.

65 En el primer número de Les Cahiers de la recherche architecturale, aparecen entre otros textos: el capítulo de un libro de Aymonino ("Le rôle des capitales du XIXe siècle"); un extracto de la investigación sobre la Italia barroca en el seno de la UP8 de Liliane Dufour, Henri Raymond y Bernard Huet; así como un texto de lonel Schein sobre los puentes habitados que representan la otra tendencia de la arquitectura urbana (la de los "proliférants") 
Cohen en la École d'Architecture de Paris-Ville$\min ^{66}$. Panerai participó activamente en la reforma educativa de 1998 y jugó un papel importante en la fundación de la École d'Architecture de Paris-Malaquais, la cual presidió desde su apertura en el año 2000, hasta el año 2004. Este último periodo marcó una ruptura tanto en su carrera docente como en su ejercicio como arquitecto y urbanista, ejercicio que había comenzado en los años 1980 y que le hizo merecedor en 1999 del Grand Prix National de l'Urbanisme. Asociado inicialmente con Alain Payeur (otro antiguo alumno de Arretche, y fundador de la agencia SEURA) en diversos proyectos arquitectónicos y urbanos en los cuales Castex participaba esporádicamente ${ }^{67}$, Panerai había tomado en 1989 el control de la agencia. Pero para 1993, instalado ya definitivamente en París, Panerai abandona la agencia SEURA, y da el paso definitivo para fundar su propia agencia ${ }^{68}$.

La reedición hecha en una misma colección por Parenthèses, de Formes urbaines: de l'îlot à la barre (1997); de Analyse urbain (1999); y de Projet urbain (1999), obedece directamente a los intereses propios y específicos de Panerai en aquel momento de su carrera. Primero que todo, hay que señalarlo, los nombres de los autores no aparecen ya ubicados por orden alfabético como sucedió en la edición de 1977: ahora, el nombre de Panerai sobresale sobre los otros. En el caso de De l'îlot à la barre, el texto del libro no sufre casi ninguna alteración, correspondiendo casi palabra por palabra al texto de 1977; pero aparecen en cambio nuevos paratextos tanto al inicio como al final del libro, lo que sin duda contribuye a recodificar la lectura del mismo. El prefacio $^{69}$ es firmado por Manuel de Solà-Morales, gran amigo y homólogo barcelonés de Panerai, y un emblemático representante español tanto en la práctica como en la docencia del "retour à la ville" [retorno a la ciudad]. Un nuevo prólogo de Panerai se esfuerza por legitimar a posteriori el libro de 1977 -en particular su tono polémico-, y a bloquear ciertas objeciones o confusiones que este pudo haber suscitado en aquel entonces. Por último, aparece un nuevo capítulo conclusivo titulado "Construire la ville: 1975-1995" que viene a reemplazar la conclusión de 1977: en este nuevo texto, esta vez en versión española (Castex, Depaule, y Panerai, 1986), Panerai traslada el contenido de los capítulos precedentes bajo una forma más prescriptiva; en últimas,

66 Denominada anteriormente como UP1 [Unité Pédagogique 1], fundada en 1969.

67 Por ejemplo, un proyecto de vivienda en la rue Saint-Fargeau (1984), de lado y lado del pasaje Gambetta, u otra en la manzana que rodea el inmueble de Aldo Rossi cerca à la Cité de la Musique en La Villette.

68 En asocio con Dominique Petermüller desde 2005, Ateliers Philippe Panerai pasó a ser la SELARL Panerai-Petermüller, architecture, urbanisme, paysage urbain.

69 Este texto es la traducción ampliada del prefacio para la edición española del libro (1986). indica la manera correcta de interpretar el libro y de aplicarlo al urbanismo, desmarcándose claramente de ciertas doctrinas contemporáneas con las cuales podría ser vinculado erróneamente, y que iban desde el "îlot ouvert" de Christian de Portzamparc, hasta la "ville européenne" de Léon Krier y Maurice Culot ${ }^{70}$, o el New Urbanism estadounidense.

En la versión de 1997, el libro se asemeja mucho más a un manual de urbanismo o a un catálogo de modelos de composición urbana, que a un informe de investigación científica sobre la dialéctica socio-espacial. Puede ser que incluso tras treinta años de su redacción original, parezca un poco caduco en el terreno mismo de la investigación. Un poco antes, Pierre Merlin -fundador del Institut Français d'Urbanismeal realizar un balance sobre los últimos "treinta años de investigación urbana", pasaba de largo sobre los trabajos de la ADROS, que habían sido sin embargo numerosos:

Desafortunadamente, el enfoque morfológico relanzado hacia 1960 por arquitectos italianos (Muratori, Caniggia, Rossi, Aymonino, Gregotti, etc.) pero que había sido iniciado por historiadores y geógrafos franceses y alemanes desde el periodo de entreguerras, parece carente de bases científicas serias. Existen no obstante algunos trabajos -aquellos sobre el sector de Les Halles en París realizados por el equipo Chastel-Boudon en Francia, o aquellos de M.R.G Conzen y J.W.R. Whitehand en Gran Bretaña- desarrollados por historiadores y geógrafos que revelan la imposición de determinantes del tejido urbano sobre las formas urbanas, y que han sentado las bases de una metodología perfectamente operacional $^{71}$. (Merlin, 1994, 62)

El citado Jeremy Whitehand, de la University of Birmingham, fue el fundador en 1993 y principal figura, de una red internacional de investigación bautizada International "Seminar of Urban Form" - ISUF, que agrupaba investigadores especializados en morfología urbana. Los referentes franceses en dicha organización fueron Michel Darin y Jean Castex, este último además, sucesor de Panerai en la dirección del LADRHAUS y coorganizador en 1998 del encuentro anual del ISUF en Versailles. Y fue justamente uno de los pilares del ISUF, el arquitecto y urbanista Ivor Samuels, quien en 2004 se encargó de la publicación de la primera edición en inglés de De l'îlot à la barre: Samuels, por entonces docente en el Joint Centre for Urban Design de la Oxford Brookes University en el Reino Unido, situó esta

\footnotetext{
$70 \mathrm{Al}$ respecto, se celebró el Coloquio internacional "La reconstruction de la ville européenne" (Bruselas, 15-17 de noviembre de 1978), organizado por Maurice Culot y Robert-Louis Delevoy. Participaron además, tanto Castex, como Panerai.

71 Merlin, P. (1994). Trente ans de recherche urbaine. Les Annales de la recherche urbaine, 64, 62.
} 
iniciativa en el campo típicamente anglosajón del urban design.

En la parte final de la versión en inglés titulada Urban Forms: the Death and Life of the Urban Block, Ivor Samuels firma un largo epílogo en donde intenta extrapolar las conclusiones presentadas por Panerai, esta vez hacia las problemáticas anglo-americanas (2004, 168-204). Tejiendo desde su propia óptica los hilos históricos presentes desde ambos lados del Atlántico en el urban design -desde las garden cities hasta el New Urbanism-, Samuels termina su texto analizando cuatro ejemplos. Tres de ellos se inscribían precisamente en el New Urbanism, sobresaliendo Seaside, una estación balnearia en Florida diseñada en los años 1980 por Andres Duany y Elizabeth Plater-Zyberk; y Poundbury, una extensión de la pequeña ciudad de Dorchester, concebida a partir de 1993 por Léon Krier, personaje que paradójicamente ha sido siempre abiertamente criticado por Panerai debido a su postura reaccionaria y neotradicional (Panerai, 1979, 3).

\section{Tiempos}

Al observar De l'îlot à la barre desde la distancia, pareciera ser el caballo de batalla de una generación contra otra: los jóvenes docentes-investigadores surgidos de Mayo del 68 reivindicando el "retour à la ville", contra los peces gordos representados por sus poderosos patrones de atelier durante los Treinta Gloriosos (en otras palabras, los arquitectos y urbanistas de la Reconstrucción y de los grands ensembles, tan crudamente vilipendiados). Sin embargo, el libro revelaba otros frentes de batalla para aquella generación de baby-boomers. Con la reedición en 1997 de De l'îlot à la barre y en un momento decisivo de la carrera profesional de Panerai, el libro puso de nuevo los focos sobre él y especialmente en el campo del urbanismo, con la definición de lo que debiera ser el proyecto urbano: cuidadoso con los usos cotidianos, sensible a las escalas, rico en modelos arquitectónicos heredados, pero hostil a todo gusto excesivo por el pasado en el plano estilístico. En 2004, nuevamente en el plano de la investigación urbana, reapareció De l'îlot à la barre, aunque desde el seno de una red internacional, eludiendo de esta forma las objeciones y críticas que con el tiempo habían encontrado en Francia este tipo de estudios tipo-morfológicos. La historia de este libro revela a lo largo de sus sucesivas reediciones, un distanciamiento progresivo de sus diferentes autores, así como la evolución de los usos del texto dados inicialmente por ellos, que en un principio fueron colectivos y que con el tiempo se volvieron más particulares e incluso divergentes.

La permanencia de De l'îlot à la barre parece hoy la señal de una renovada y perpetua vigencia: manifiesto de un retorno a la realidad pro- saica de la ciudad y por consiguiente de una especie de revolución reaccionaria de la cual el propio Panerai ha señalado la paradoja (Panerai, 1979), este libro es actualmente uno de los raros sobrevivientes de la producción científica de aquel momento ya distante y singular de la arquitectura francesa. Leerlo nos proporciona la misma impresión que se tiene al escuchar a Panerai, antihéroe aparentemente indiferente que maneja alternativamente la razón y el sentido común, y agrimensor insaciable de las urbanizaciones más contemporáneas sobre las cuales dirige la mirada propia de un amateur del siglo XIX. Presente desde hace cuatro décadas en los principales escenarios del mundo arquitectónico, Panerai se las ingenia siempre para ser una excepción, para ocupar allí un lugar a la vez influyente y desfasado, central y periférico. Su estrategia para participar a partir de 2007 en el proyecto denominado "Grand Pari de I'agglomération parisienne" [un juego de palabras en francés: la gran apuesta por un Gran París] es diciente: como miembro del consejo científico del mismo y a pesar de no figurar entre los equipos seleccionados en el marco del concurso de ideas de dicho proyecto, Panerai publicó de forma bastante oportuna un libro de síntesis dedicado exclusivamente al tema, titulado Paris métropole: formes et échelles du Grand Paris, con lo cual aseguró su presencia en el centro de los debates oficiales tanto en el proyecto "Paris Métropole" como en el de "Grand Pari(s) 72". ¿Tendrá acaso este libro, una longevidad como la lograda por De l'îlot à la barre?

72 Panerai, P. (2008). Paris Métropole : formes et échelles du Grand Paris. Paris: Ed. de la Villette.

\section{Listado de ediciones y traducciones del libro (en orden cronológico)}

(1975). De l'îlot à la barre: contribution à une définition de l'architecture urbaine [rapport de recherche "Evolution comparée des modèles architecturaux et des modèles culturels dans la ville industrielle d'Haussmann à Le Corbusier", vol. 1]. Paris: ADROS / CORDA.

(1977). Formes urbaines: de l'îlot à la barre. Paris: Dunod. [reimpreso en 1980 y 1985]

(1981). Isolato urbano e città contemporanea. Milano: Città Stdui Edizioni.

(1984). De rationele stad: van bouwblok tot wooneenheid. Nimègue: Sun Architectuur.

(1985). Vom Block zur Zeile: Wandlungen der Stadtstruktur. Wiesbaden: Vieweg.

(1986). Formas urbanas: de la manzana al bloque. Barcelona: Editorial Gustavo Gili. [prefacio de Manuel de Solà-Morales]

(1989). Urbane Forme. Belgrado: Gradevinsk Knjiga.

(1993). [Formes urbaines: de l'îlot à la barre], Tokyo: Instituto Kajima.

(1997). Formes urbaines: de l'îlot à la barre. Marseille: Parenthèses. [reimpreso en 2001 y 2012]

(2004). Urban Forms: the Death and Life of the Urban Block. Oxford: Architectural Press.

Otras traducciones se encuentran en curso (al árabe, al chino, y entre otras lenguas) 


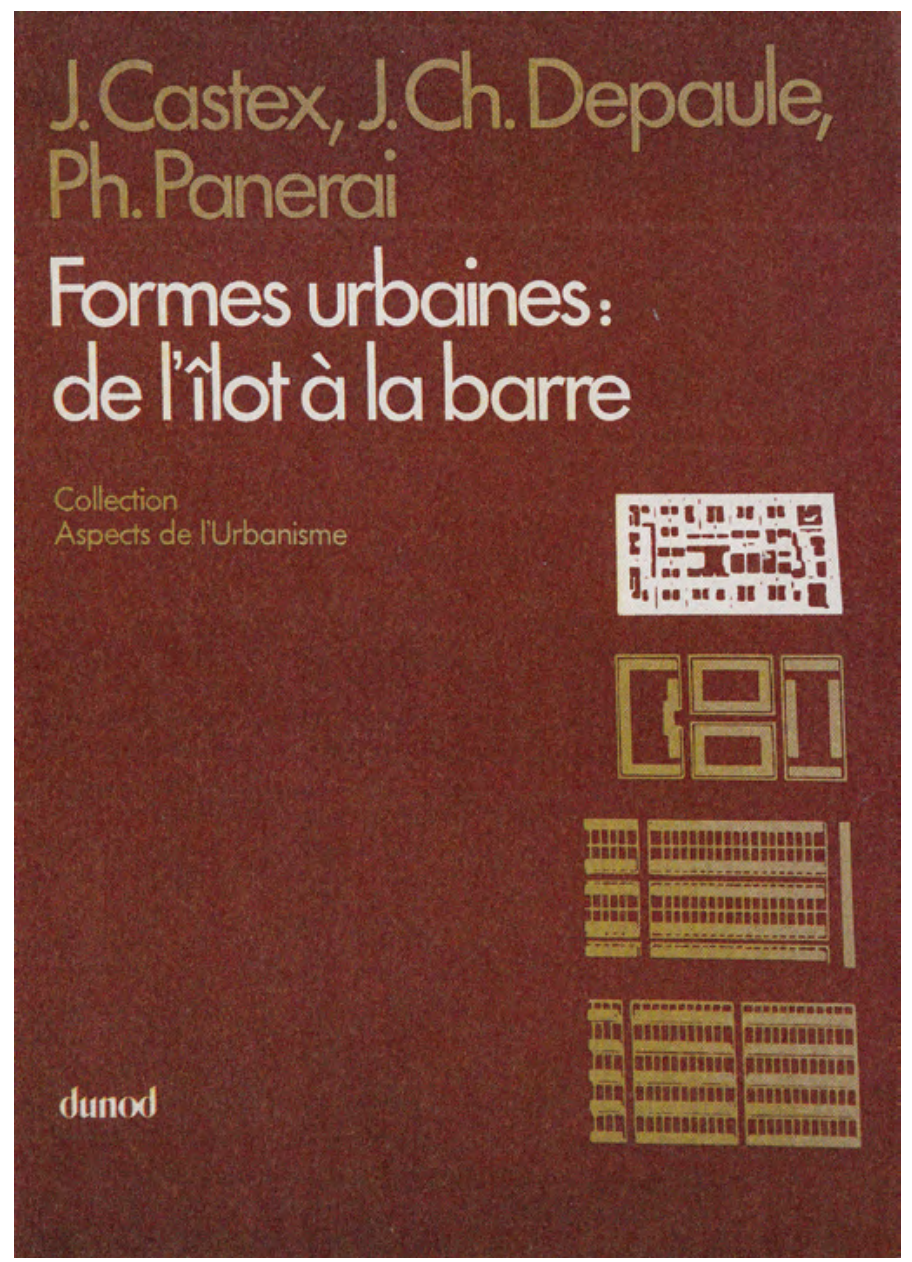

(A) Figura 1. Portada de la edición de 1977, por la editorial DUNOD.
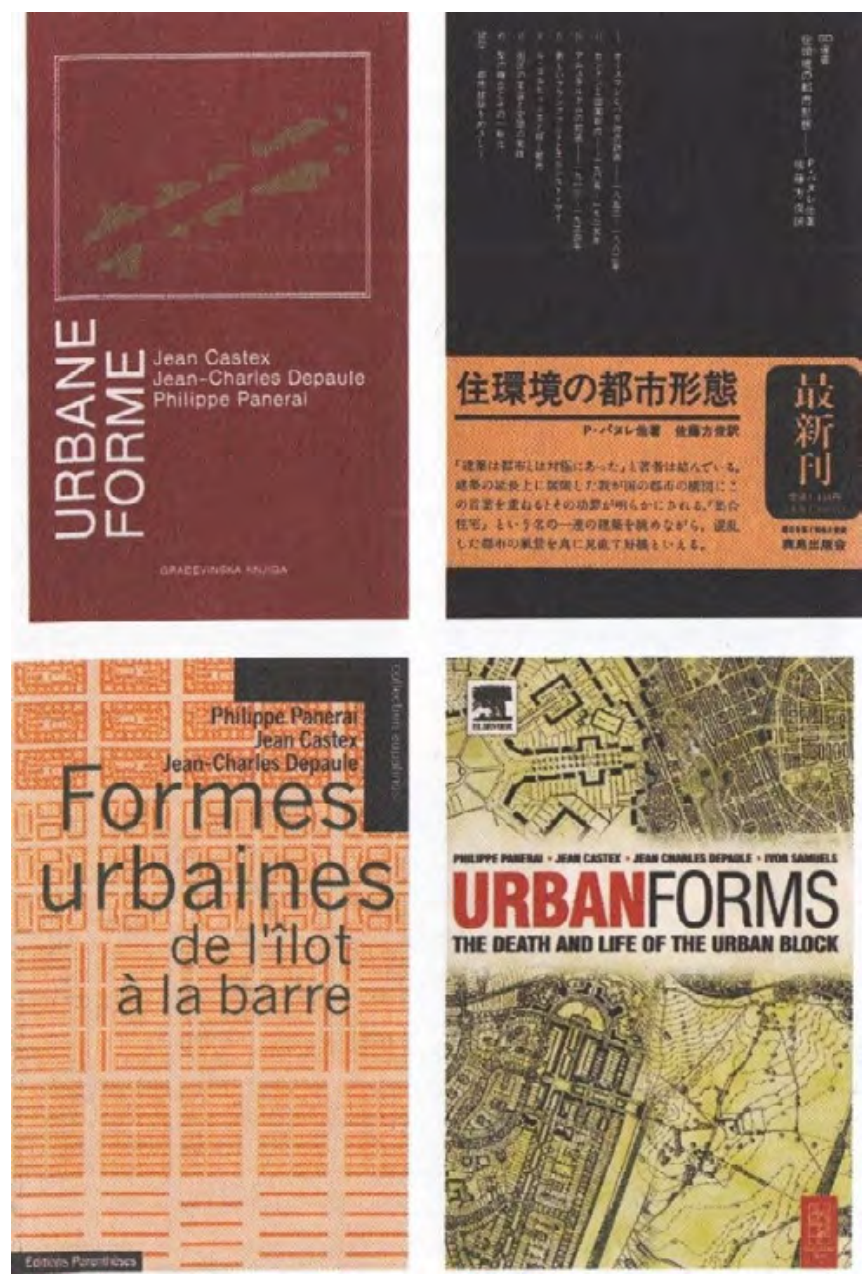
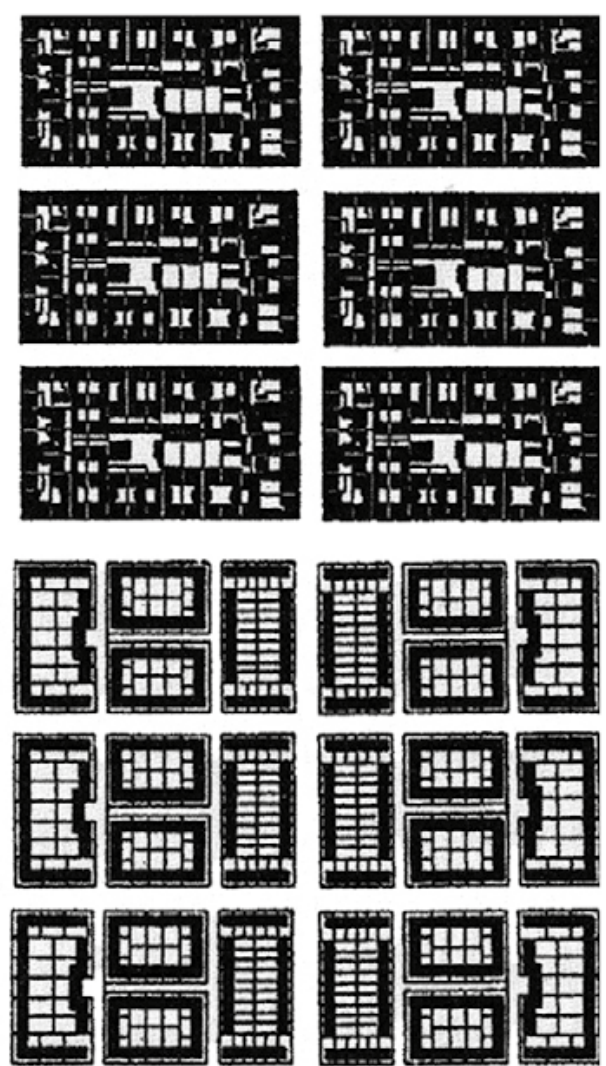

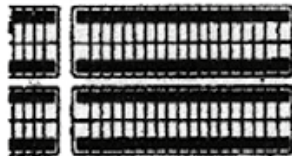

曲

曲

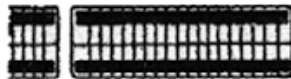

回

का

iimini (III)

inimin uminim

iniiini Tinimini

IIIIII)

(1)

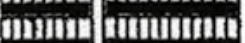

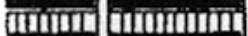

IIIIIII IIIIIIIIIII

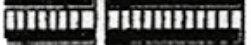
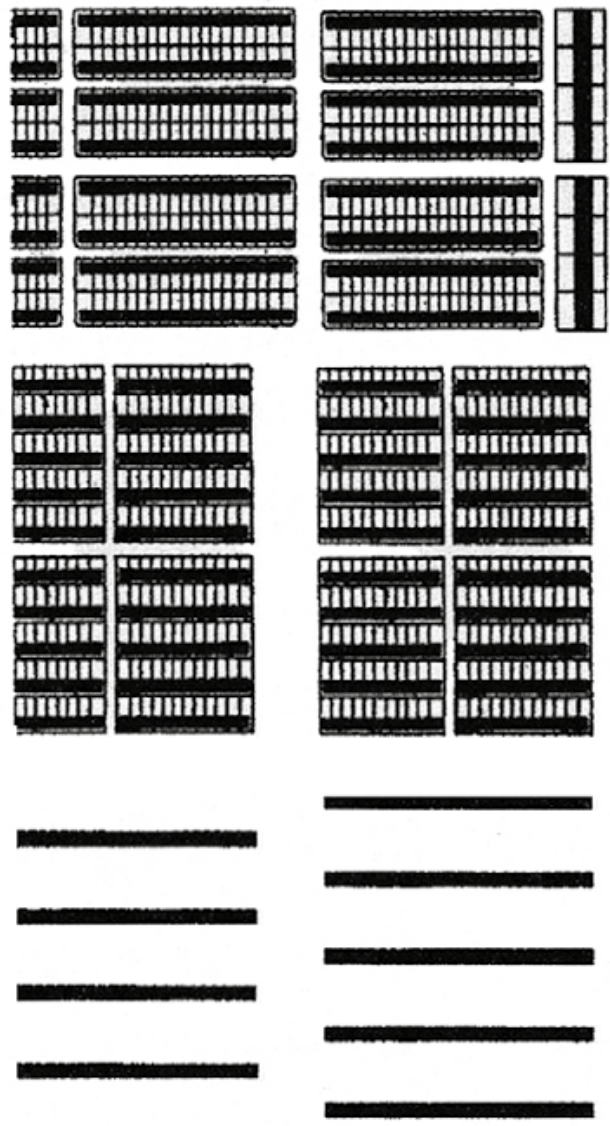

(III)

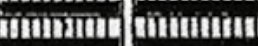

iniminim himinim

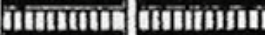

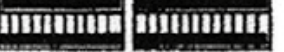

mimm

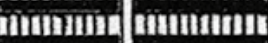

intrimin Himinimin

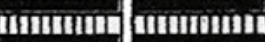

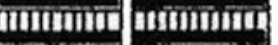

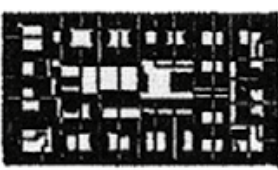

E:Fin: in of

:

$=1-\infty i n$

다의 in 11 in

Eif it/ in का

:ieIn工z:

जiti in in inin
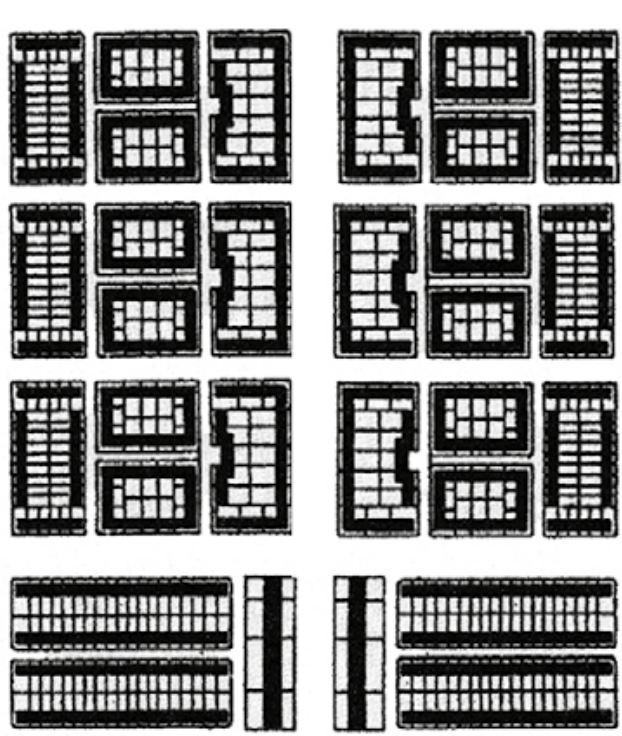

-

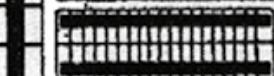
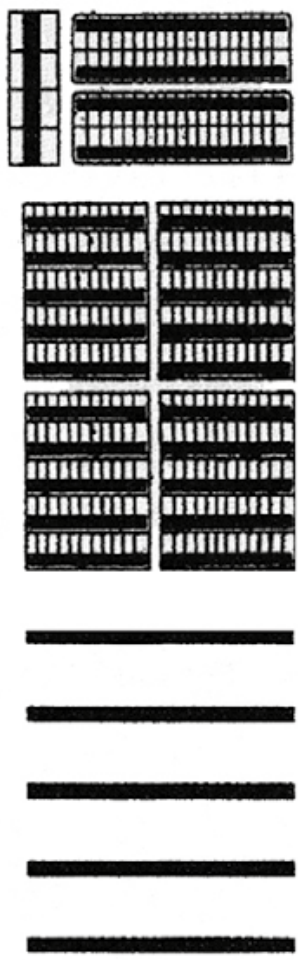

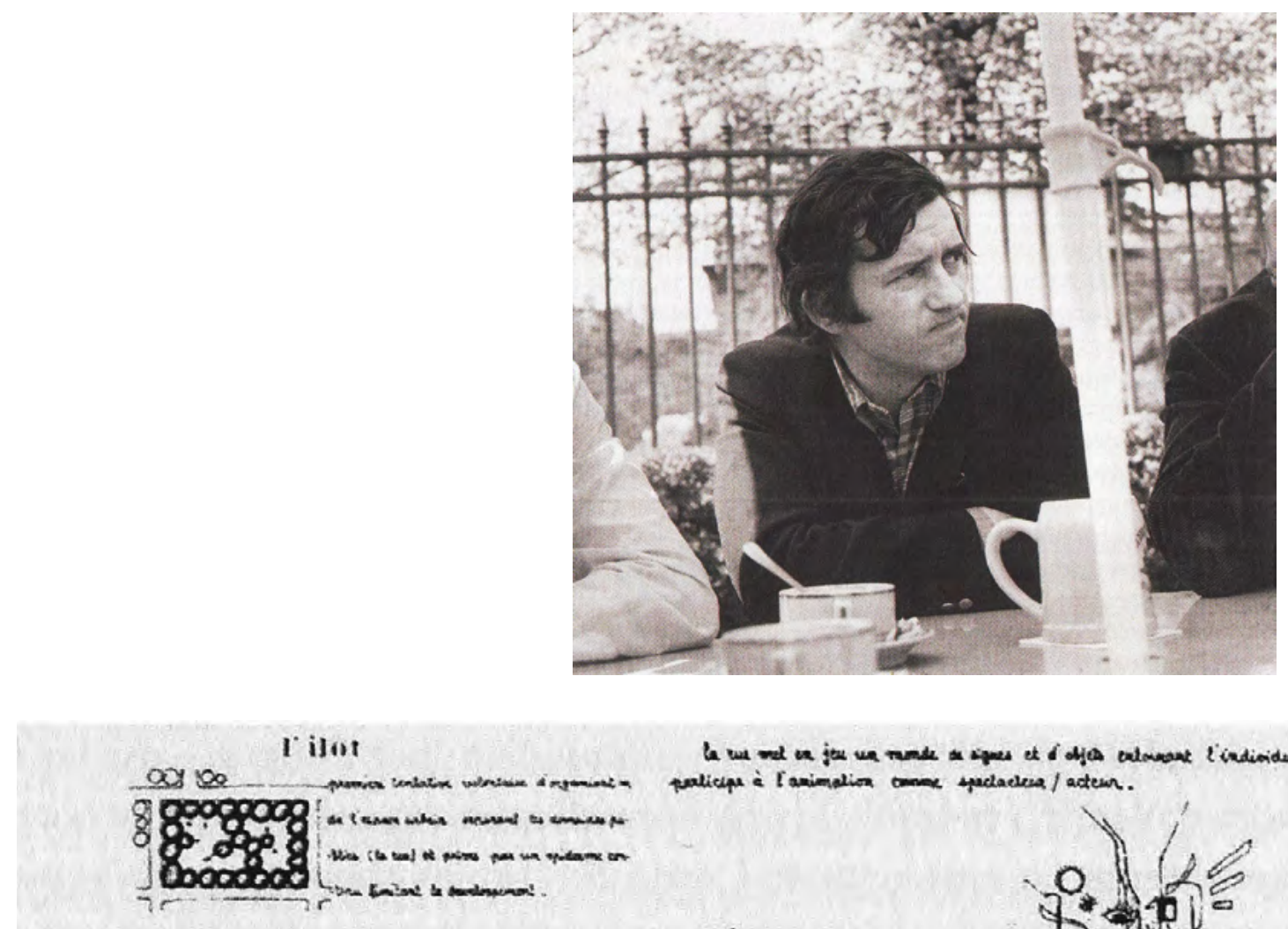

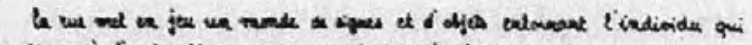

exolution de lïlot

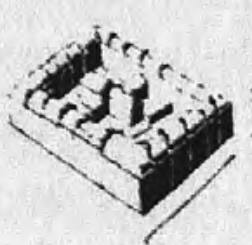

IVIIIs

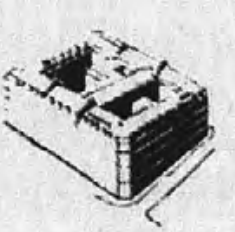

Lutussmumn

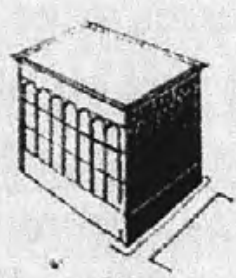

chiculys

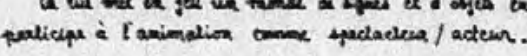
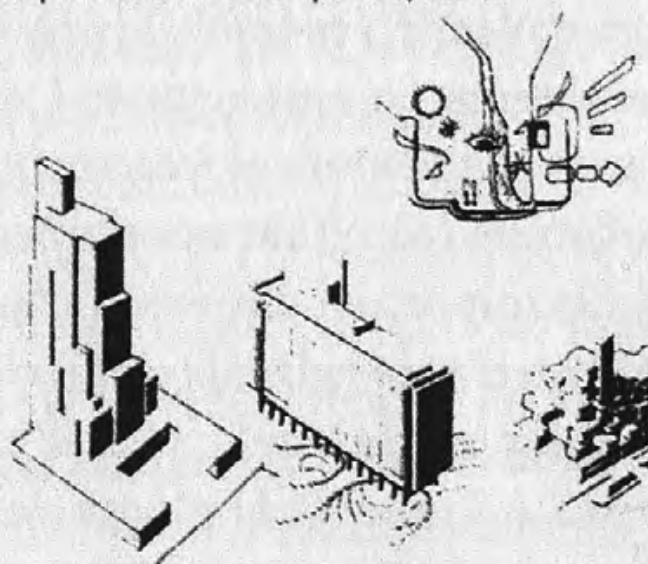

new:yorli marseilles
\& Figura 4. Philippe Panerai en 1971, en la terraza de un café en Versailles. (Photo : Frédéric Benrath)

\&igura 5. Extracto de un panel presentado por Panerai en el marco del Grand Prix International d'Urbanisme et $\mathrm{d}^{\prime}$ Architecture, concedido por la asociación "Construction \& Humanisme" en su segundo encuentro anual, en Cannes durante marzo de 1970.

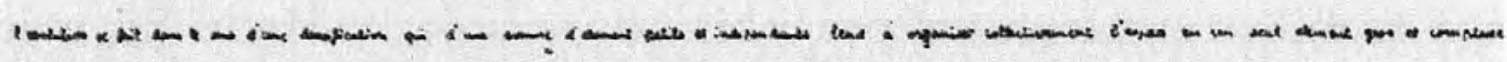

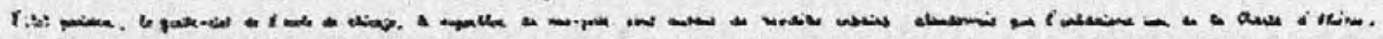

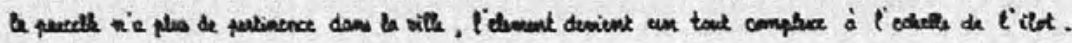

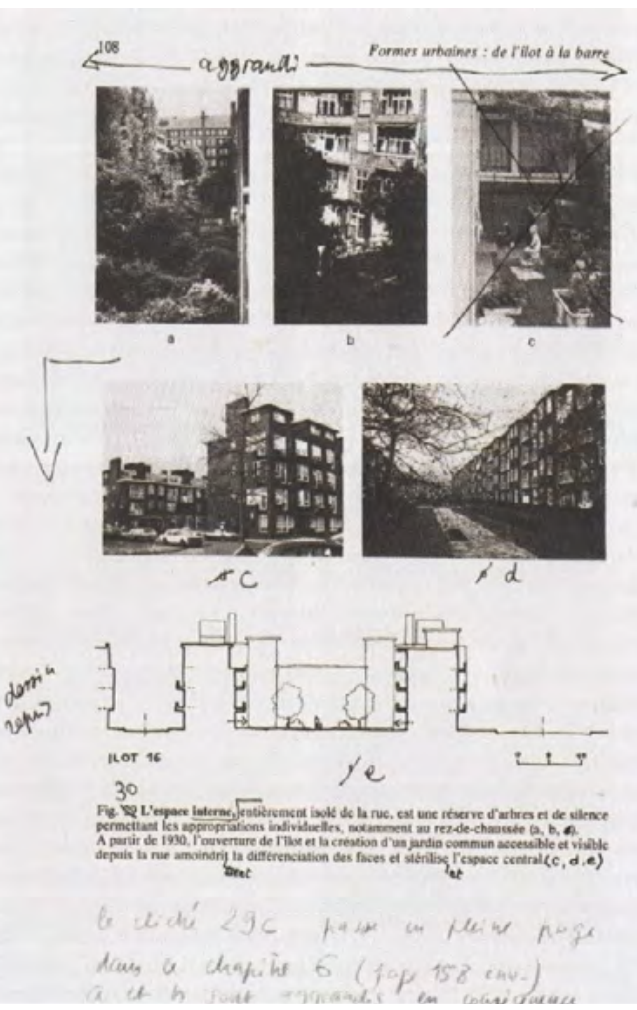

A Figura 6. Anotaciones de Philippe Panerai sobre las páginas de un ejemplar de la edición de 1977 (DUNOD), para correcciones previstas en la reedición de 1997 por la editorial Parenthèses.

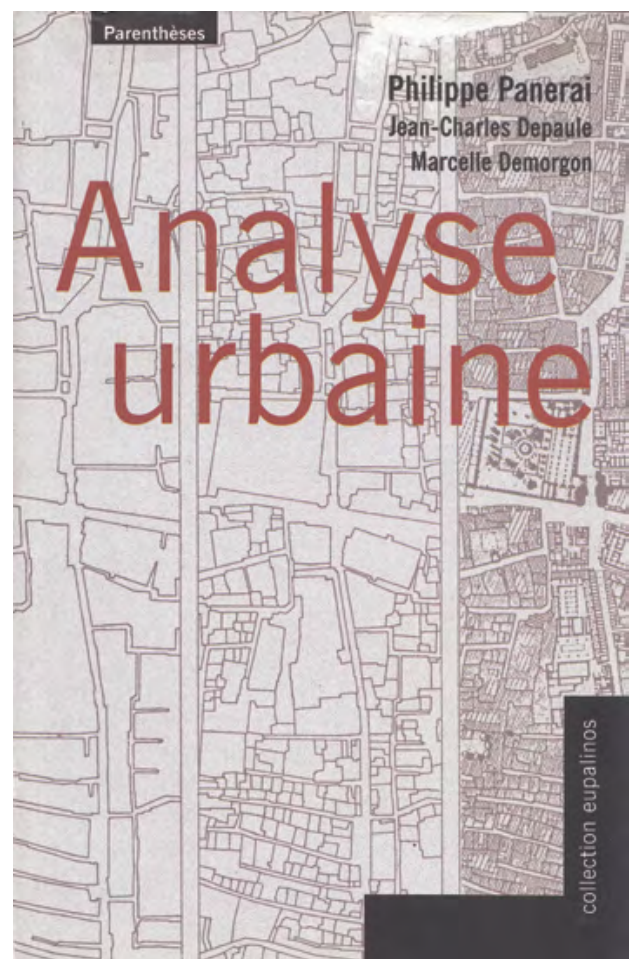

A Figura 7. Portada de la reedición de 2012 de Analyse urbaine, por la editorial Parenthèses en la colección "Eupalinos".

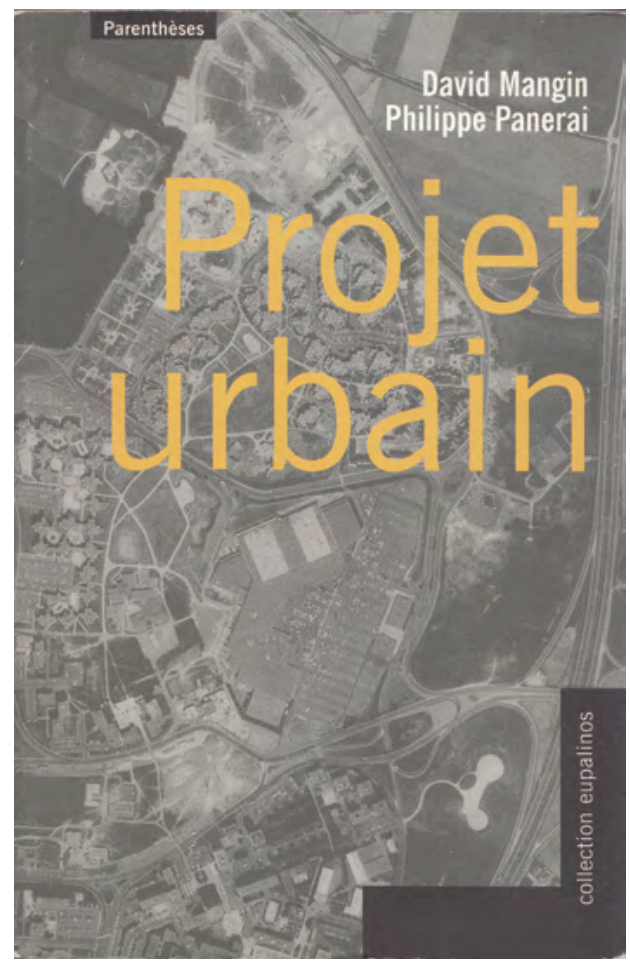

A Figura 8. Portada de la reedición de 2009 de Projet urbain, por la editorial Parenthèses en la colección "Eupalinos". 


\section{Referencias}

Amouroux, D. (2010). Louis Arretche. Gollion: Éditions InFolio.

Auzelle, R., y Jankovic, I. (1947-1967). Encyclopédie de l'urbanisme. Paris: Vincent Fréal. [31 fascículos]

Aymonino, C., Cristofoli, C., Fabbri, G., Gafferini, P., y Rossi, A. (1964). Aspetti e problemi della tipologia edilizia. Venecia: IUAV.

Aymonino, C., y Rossi, A. (1965). La formazione del concetto di tipologia edilizia. Venecia: IUAV.

Aymonino, C., Brusatin, M., Fabbri, G., Lena M., Lovero, P., Lucianetti, S., y Rossi, A. (1966). La Città di Padova, saggio di analisi urbana. Roma: Officina Edizioni.

Barthes, R. (1970). Sémiologie et urbanisme. L'Architecture d'aujourd'hui. 153, 11-13.

Boudon, F., Chastel, A., Cousy, H., y Hamon, F. (1977). Système de l'architecture urbaine. Le quartier des Halles à Paris. Paris: Éditions du CNRS.

Castex, J., y Pannerai, P. (1970). Notes sur la structure de l'espace urbain. L'Architecture d'aujourd'hui. 153, 30-33.

Castex, J., Depaule, J-Ch., y Pannerai, P. (1975). De l'îlot à la barre : contribution à une définition de l'architecture urbaine. Versailles: ADROS/CORDA.

Castex, J., Depaule, J-Ch., y Panerai, P. (1977). Formes urbaines : de l'îlot à la barre. Paris: Dunod.

Castex, J. (1979). Versailles, lecture d'une ville. Les Cahiers de la recherche architecturale, 4, 63-78.

Castex, J. (1980). Préface. En Demorgon, M., Depaule, J. Ch., Panerai, P., y Veyrenche, M., Éléments d'analyse urbaine. Bruselas: Archives d'Architecture Moderne - AAM.

Castex, J. (1990). Renaissance, baroque et classicisme. Histoire de l'architecture, 14201720. Paris: Éditions Hazan [reeditado en 2004 por Éditions de la Villette]

Castex, J. (1997). François Mansart : étendue et marge du projet classique. Tesis doctoral. Institut Français d'Urbanisme / Université Paris 8, Paris, Francia.

Castex, J., Depaule, J-Ch., y Panerai, P. (2012). Formes urbaines : de l'îlot à la barre. Paris: Éditions Parenthèses.

Céleste, P. (1984). Vocabulaire traditionnel des dessins d'architecture. En Dethier, J. (Dir.), Images et imaginaires de l'architecture (pp.150-158), Paris: Centre Georges Pompidou.

Cohen, J-L. (1984). La coupure entre architectes et intellectuels, ou les enseignements de I'italophilie. Paris: École d'Architecture de Paris-Villemin [reeditado y aumentado en 2015 por Éditions Mardaga].

Colloque international : "La reconstruction de la ville européenne", Bruselas, 15-17 de noviembre de 1978.

Chaslin, F. (1999). Philippe Panerai, le grand îlotier. En Grand Prix de I'Urbanisme 1999 Paris: Ministère de l'Equipement, des Transports et du Logement.

Chiffard, J-F., Delorme, J-C. (1977). Les HBM et la ceinture de Paris. En Gülgönen, A., Laisney, F. (Dirs.), Morphologie urbaine et typologie architecturale. Paris: IERAU/CORDA

Choay, F. (1969). Espacements. L'évolution de l'espace urbain en France. Paris: Éditions du Seuil.

Choay, F. (1970). Remarques à propos de sémiologie urbaine. L'Architecture d'aujourd'hui, 153, 9.

De Solà-Morales, M. (1997). Préface. En Castex, J., Depaule, J-Ch., y Panerai, P., Formes urbaines : de l'îlot à la barre. Paris: Éditions Parenthèses.

Demorgon, M., Depaule, J. Ch., Panerai, P., y Veyrenche, M. (1980). Éléments d'analyse urbaine. Bruselas: Archives d'Architecture Moderne - AAM.

Demorgon, M., Depaule, J. Ch., Panerai, P. (1999). Analyse urbaine. Marseille: Éditions Parenthèses.

Depaule, J. Ch., (1979). Les sauvages de I'architecture. Tesis doctoral. Université Paris X Nanterre, Paris, Francia.

Depaule, J-Ch. (1996). La typologie architecturale. En Castex, Cohen, J-L., J., Depaule, J-Ch., (Eds.), Histoire urbaine, anthropologie de l'espace. Paris: Éditions du CNRS.

Devillers, C. (1974). Typologie de I'habitat et morphologie urbaine. L'Architecture d'aujourd'hui, 174, 18-22.

Dufour, L., Huet, B., Raymond, H. (1977). Urbanistique et société baroques. Paris: IERAU.

Foucault, M. (1984). Des espaces autres. Architecture-Mouvement-Continuité-AMC, 5, 46-49.

Frey, J-P. (2006). Henri Raymond: portrait d'un sociologue. Vers une histoire architecturale de la société. Paris: L'Harmattan.

Gerosa, P. (1993). La ville comme artefact. La question typologique et la morphologie. En Éléments pour une histoire des théories sur la ville comme artefact et forme spatiale, XVIIle-XXe siècles (pp. 177-252). Strasbourg: Université des Sciences Humaines.

Grassi, G. (dir.). (1975). Das neue Frankfurt, 1926-1931. Bari: Edizioni Dedalo.

Grassi, G. (1983). Das neue Frankfurt et I'architecture du nouveau Frankfurt. En Grassi, G. L'Architecture comme métier et autres écrits (pp. 89-124). Liège: Éditions Mardaga.

Groupe Syntaxe. (1972). Autopsie d'un village, Marcillac. L'Architecture d'aujourd'hui, $164,22-24$

Groupe Syntaxe. (1974). Parti pris. Architec ture-Mouvement-Continuité - AMC, 34.

Grudet, I. (2005). L'Histoire de I'urbanisme de Pierre Lavedan, 1919-1955 : entre savoir et action. Tesis doctoral. Université Paris VIII, Paris, Francia.

Gülgönen, A., Laisney, F. (Dir.). (1977). Morphologie urbaine et typologie architecturale. Paris : IERAU / CORDA.

Gülgönen, A., Laisney, F., y Pietu, M. (1979). Nancy : la reprise figurative de la ville par le projet baroque. Les Cahiers de la recherche architecturale, 4, 79-87.

Hanrot, S. (2002). A la recherche de l'architecture: essai d'épistémologie de la discipline et de la recherche architecturales. Paris : L'Harmattan.

Lavedan, P. (1926). Histoire de l'urbanisme. Antiquité et Moyen Âge. Paris: H. Laurens

Lavedan, P. (1941). Histoire de I'urbanisme. Renaissance et temps modernes. Paris: $\mathrm{H}$ Laurens

Lavedan, P. (1952). Histoire de I'urbanisme. Époque contemporaine. Paris: H. Laurens

Lichnerowicz, A. (Dir.). (1970). La Recherche architecturale. Paris: Ministère des Affaires Culturelles.

Loyer, F. (1987). Paris XIXe siècle: I'immeuble et la rue, Paris : Éditions Hazan.

Mangin, D. y Panerai, P. (1999). Projet urbain. Marseille: Éditions Parenthèses.

Merlin P. (1994). Trente ans de recherche urbaine. Les apports de la Géographie. Les Annales de la recherche urbaine, 64, 61-63. https://www.persee.fr/doc/aru_0180930x 1994 num 6411819

Muratori, S. (1960). Studi per une operante storia urbana di Venezia. Rome: Istituto poligrafico dello Stato. [2 volumenes]

Panerai, P. (1969). Structures urbaines et villageoises dans le Haut-Rouergue, analyse typologique de 12 agglomérations. Tesis de maestría. Institut d'Urbanisme de Dauphine, Paris, Francia.

Panerai, P. (1975). Avant-propos. En Castex, J. Depaule, J-Ch., y Pannerai, P., De l'îlot à la barre : contribution à une définition de l'architecture urbaine. Versailles: ADROS/CORDA.

Panerai, P. (1979). Typologies. Les Cahiers de la recherche architecturale, 4, 3-20.

Panerai, P. (1986). Construir la ciudad. En Formas urbanas: de la manzana al bloque (pp. 172-182). Barcelona: Editorial Gustavo Gili.

Panerai, P. (2008). Paris Métropole : formes et échelles du Grand Paris. Paris: Éditions de la Villette.

Panerai, P. (2012). "Les territoires de l'architecture: petit parcours de l'analyse urbaine" en Marnes. Documents d'architecture, 2, 348-377.

Raymond, H., y Segaud, M. (1970). Analyse de l'espace architectural. Paris: Centre de Recherche d'Architecture, d'Urbanisme et de Construction.

Rossi, A. (1964). Contributo al problema de rapporti tra tipologia edilizia e morfologia urbana. Esame di un'area studio di Milano. Milan: ILSES.

Rossi, A. (1981). L'Architecture de la ville. Paris: Éditions de L'Équerre.

Rousseau, J-J. (1753/1755/1761/763). Essai sur l'origine des langues. En J-J Rousseau. (1781). OEuvres posthumes de J-J Rousseau. Genève: Le Pléiade Édition.

Roze, T. (1973). Ernst May, Frankfurter Siedlungen. Zurich: ETH.

Roze, T. (1997). Louis Arretche architecte, $1905-$ 1991. DEA, Université Paris 1.

Samuels, I. (2004). An Anglo-American Postscript. En Urban Forms: the Death and Life of the Urban Block (pp. 168-204). Oxford: Architectural Press.

Stinco, A. (2012). Mes Beaux-Arts, Criticat, 9, 24-45.

Tafuri, M. (1971). Socialdemocrazia e città nella Germania di Weimar. Contropiano, 1, 259-311.

Tafuri, M. (1976). Théories et Histoire de I'architecture. Paris: SADG.

Tapie, G. (2000). Les Architectes: mutations d'une profession. Paris: L'Harmattan.

Techniques et architecture, octubre de 1975 (n 306)

Techniques et architecture, enero de 1976 ( $n^{\circ}$ 307)

Trincanato, R. (1948). Venezia Minore. Milan: Edizioni del Milione.

Viala, A. (1992). Qu'est-ce qu'un classique?, Bulletin des bibliothèques de France, 37 (1), 10.

Violeau, J-L. (2005). Les Architectes et Mai 68. Paris: Éd. Recherches.

Violeau, J-L. (2010). Les architectes et Mai 81. Paris: Éd. Recherches.

Edelmann, F. Un livre-repère. (1978, marzo 3). Le Monde, p. 25.

\section{Fuentes orales}

Entrevista a Philipe Panerai realizada por Pierre Chabard en Paris, 12 de noviembre de 2008.

Entrevista a Philipe Panerai realizada por Pierre Chabard en Paris, 27 de noviembre de 2008 .

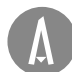



(1) Portada: Las bovedadas de Bramante.

Fotografía: Luis Alberto Martínez Camacho (2021) CC BY-NC

\section{(ब) (1) (\$)}

(A) Orientación editorial

\section{Enfoque y alcance}

La Revista de Arquitectura (Bogotá) ( (ISSN 1657-0308 Impresa y E-ISSN 2357-626X en línea) es una publicación científica seriada de acceso abierto, arbitrada mediante revisión por pares (doble ciego) e indexada, en donde se publican resultados de investigación originales e inéditos.

Está dirigida a la comunidad académica y profesional de las áreas afines a la disciplina. Es editada por la Facultad de Diseño y el Centro de Investigaciones (CIFAR) de la Universidad Católica de Colombia en Bogotá (Colombia).

La principal área científica a la que se adscribe la Revista de Arquitectura (Bogotá) según la OCDE es:

Gran área: 6. Humanidades

Área: 6.D. Arte

Disciplina: 6D07. Arquitectura y Urbanismo

También se publican artículos de las disciplinas como 2A02, Ingeniería arquitectónica; 5C03, Estudios urbanos (planificación y desarrollo); 6D07, Diseño.

Los objetivos de la Revista de Arquitectura (Bogotá) son:

- Promover la divulgación y difusión del conocimiento generado a nivel local, nacional e internacional

- Conformar un espacio para la construcción de comunidades académicas y la discusión en torno a las secciones definidas.

- Fomentar la diversidad institucional y geográfica de los autores que participan en la publicación.

- Potenciar la discusión de experiencias e intercambios científicos entre investigadores y profesionales.

- Contribuir a la visión integral de la arquitectura, por medio de la concurrencia y articulación de las secciones mediante la publicación de artículos de calidad.

- Publicar artículos originales e inéditos que han pasado por revisión de pares, para asegurar que se cumplen las normas éticas, de calidad, validez científica, editorial e investigativa.

- Fomentar la divulgación de las investigaciones y actividades desarrolladas en la Universidad Católica de Colombia.
Palabras clave de la Revista de Arquitectura (Bogotá): arquitectura, diseño, educación arquitectónica, proyecto y construcción, urbanismo.

Idiomas de publicación: español, inglés, portugués y francés. Título abreviado: Rev. Arquit.

Titulo corto: RevArq

\section{Políticas de sección}

La revista se estructura en tres secciones correspondientes a las líneas de investigación activas y aprobadas por la institución, y dos complementarias, que presentan dinámicas propias de la Facultad de Diseño y las publicaciones relacionadas con la disciplina.

Cultura y espacio urbano. En esta sección se publican los artículos que se refieren a fenómenos sociales en relación con el espacio urbano, atendiendo aspectos de la historia, el patrimonio cultural y físico, y la estructura formal de las ciudades y el territorio.

Proyecto arquitectónico y urbano. En esta sección se presentan artículos sobre el concepto de proyecto, entendido como elemento que define y orienta las condiciones proyectuales que devienen en los hechos arquitectónicos o urbanos, y la forma como estos se convierten en un proceso de investigación y nuevo de conocimiento. También se presentan proyectos que sean resultados de investigación, los cuales se validan por medio de la ejecución y transformación en obra construida del proceso investigativo. También se contempla la publicación de investigaciones relacionadas con la pedagogía y didáctica de la arquitectura, el urbanismo y el diseño.

Tecnología, medioambiente y sostenibilidad. En esta sección se presentan artículos acerca de sistemas estructurales, materiales y procesos constructivos, medioambiente y gestión, relacionados con los entornos social-cultural, ecológico y económico.

Desde la Facultad. En esta sección se publican artículos generados en la Facultad de Diseño, relacionados con las actividades de docencia, extensión, formación en investigación o internacionalización, las cuales son reflejo de la dinámica y de las actividades realizadas por docentes, estudiantes y egresados; esta sección no puede superar el $20 \%$ del contenido.

Textos. En esta sección se publican reseñas, traducciones y memorias de eventos relacionados con las publicaciones en Arquitectura y Urbanismo.
A Frecuencia de publicación

Desde 1999 y hasta el 2015, la Revista de Arquitectura (Bogotá) publicó un volumen al año, a partir del 2016 se publicarán dos números por año en periodo anticipado, enero-junio y julio-diciembre, pero también maneja la publicación anticipada en línea de los artículos aceptados (versión Post-print del autor).

La Revista de Arquitectura (Bogotá) se divulga mediante versiones digitales (PDF, HTML, EPUB, XML) e impresascon un tiraje de 700 ejemplares, los tiempos de producción de estas versiones dependerán de los cronogramas establecidos por la editorial.

Los tiempos de recepción-revisión-aceptación pueden tardar entre seis y doce meses dependiendo del flujo editorial de cada sección y del proceso de revisión y edición adelantado.

Con el usuario y contraseña asignados, los autores pueden ingresar a la plataforma de gestión editorial y verificar el estado de revisión, edición o publicación del artículo.
A Canje

La Revista de Arquitectura (Bogotá) está interesada en establecer canje con publicaciones académicas, profesionales o científicas del área de Arquitectura y Urbanismo, como medio de reconocimiento y discusión de la producción científica en el campo de acción de la publicación.

Mecanismo

Para establecer canje por favor descargar, diligenciar y enviar el formato: RevArq FP20 Canjes

Universidad Católica de Colombia (2021,
junio-diciembre). Revista de
Arquitectura (Bogotá), 23(2),
I-132. Doi: 10.14718
ISSN: I657-0308
E-ISSN: 2357-626X
Especificaciones:
Formato: $34 \times 24 \mathrm{~cm}$
Papel: Mate II5 g
Tintas: Negro y policromía

A Contacto

Dirección postal:

Avenida Caracas N ${ }^{0} \cdot 46-72$ Universidad Católica de Colombia Bogotá D. C., Colombia Código postal: 111311

Facultad de Diseño Centro de Investigaciones (CIFAR) Sede El Claustro. Bloque "L", 4 piso Diag. 46A N ${ }^{0 .} 15 b-10$ Editor, Arq. César Eligio-Triana

Teléfonos:

+57 (1) $3277300-3277333$

Ext. $3109 ; 3112$ o 5146
Fax: +57 (1) 2858895

Correo electrónico:

revistadearquitectura@ucatolica.edu.co cifar@ucatolica.edu.co

Página WEB:

www.ucatolica.edu.co

Vínculo Revistas científicas

http://publicaciones.ucatolica.edu.co revistas-cientificas

https://revistadearquitectura.ucatolica.edu.co/ 
